Electronic Supplementary Material (ESI) for Journal of Materials Chemistry C.

This journal is @ The Royal Society of Chemistry 2018

Electronic supporting information (ESI)

\title{
Controlling the Crystallinity and Crystalline Orientation of "Shuttlecock" Naphthalocyanine Films for Near-Infrared Optoelectronic Applications
}

Simon Dalgleish ${ }^{1,2 *}$, Louisa Reissig ${ }^{1,3}$, Yoshiaki Shuku ${ }^{1}$, Christophe Gourlaouen $^{4}$, Sergi Vela ${ }^{4}$, Kunio Awaga ${ }^{1 *}$

${ }^{1}$ Department of Chemistry and IRCCS, Nagoya University, Furo-cho, Chikusa, 464-8602 Nagoya, Japan

${ }^{2}$ Institute for Advanced Research, Nagoya University, Furo-cho, Chikusa, 464-8601 Nagoya, Japan

${ }^{3}$ Institute of Experimental Physics, Freie Universität Berlin, Arnimallee 14, 14195 Berlin, Germany

${ }^{4}$ Laboratoire de Chimie Quantique, Institut de Chimie, UMR 7177 CNRS-Université de Strasbourg, 4 rue Blaise Pascal 67081 Strasbourg, France

\section{CONTENTS:}

1) Further Experimental Details (Page 2)

2) Molecular Structure and Packing

i) Additional data for SnNPc (Page 4)

ii) Additional data for VONPc (Page 7)

3) Thin Film Characterization

i) As deposited films of SnNPc (Page 8)

ii) Solvent annealing of SnNPc (Page 10)

iii) As deposited films of VONPc (Page 14)

iv) Solvent annealing of VONPc (Page 15)

v) Templated films of SnNPc (Page 16)

vi) Templated films of VONPc (Page 18)

vii) Versatility of molecular templating (Page 19)

4) Analysis of the Absorption Spectra

i) Computational analysis (Page 21)

ii) Spectral deconvolution (Page 23)

5) Device Performance (Page 26)

6) References (Page 28) 


\section{FURTHER EXPRERIMENTAL DETAILS}

General Methods - Solvent vapor annealing was performed on amorphous films, deposited at a rate of $0.5 \AA^{-1}$, by suspending the substrates face up at $1.5 \mathrm{~cm}$ above the given solvent (Wako), or solvent mixture, in a sealed glass vial for the prescribed time. The solvent vial was previously equilibrated for $>24 \mathrm{hrs}$ at $28^{\circ} \mathrm{C}$, and the annealing times were optimized based on endpoints determined by no further change to their absorption spectra (acetone: $24 \mathrm{~h}$, xylene: $17 \mathrm{~h}$, chloroform: $4 \mathrm{~h}$, tetrahydrofuran (THF): $4 \mathrm{~h}$, Chlorobenzene:water (10:1): $17 \mathrm{~h}$, methanol (MeOH): $14 \mathrm{~h}$ ).

Molecular \& Bulk Characterization - Powder XRD signals were recorded on commercial samples using Cu Ka radiation ( $\lambda_{\mathrm{av}}=1.541874 \AA$, $40 \mathrm{kV}, 30 \mathrm{~mA}$ ) on a Rigaku Smartlab X-ray

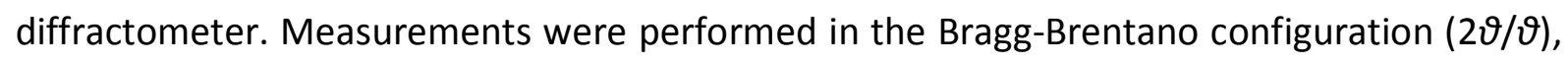
scanning the range $2-60^{\circ}$. Data were analyzed using the PDXL firmware.[1]

Film Characterization - Thin film XRD signals in different scanning geometries were recorded on $30 \times 30 \mathrm{~mm}$ silicon 100 wafers using Cu Ka radiation ( $\lambda_{\mathrm{av}}=1.541874 \AA$, $40 \mathrm{kV}, 30 \mathrm{~mA}$ ) on a Rigaku Smartlab X-ray diffractometer. As well as measurements performed using parallelbeam optics. In addition to symmetric scans $(2 \vartheta / \vartheta)$, the samples were also measured in asymmetric mode $\left(2 \vartheta, \omega=0.4^{\circ}\right)$ and in-plane mode $\left(2 \vartheta \chi / \varphi, 2 \vartheta=\omega=0.4^{\circ}\right)$, with appropriate optics. In all cases, the scanning range was $2-35^{\circ}$ (step $0.02^{\circ}$ at $0.2^{\circ} / \mathrm{min}$ ). Data were analyzed using the PDXL firmware.[1]

Device Fabrication \& Testing - Transistor measurements were performed on $50 \mathrm{~nm}$ films of SnNPc deposited onto bottom-contact bottom-gate (BCBG) interdigitated Au array electrodes (source and drain) with a channel width of $W=4 \mathrm{~cm}$ and channel length of $L=50 \mu \mathrm{m}$, which were prepared by standard photolithographic methods on surface oxidized $n$-doped silicon substrates $\left(\mathrm{SiO}_{2}: 300 \mathrm{~nm}\right)$. Output and transfer characteristics were recorded under vacuum and dark conditions on a Keithley2636A SourceMeter.

The device structure for photocurrent measurements is shown in Figure S1, and the device assembly is described in the main article.
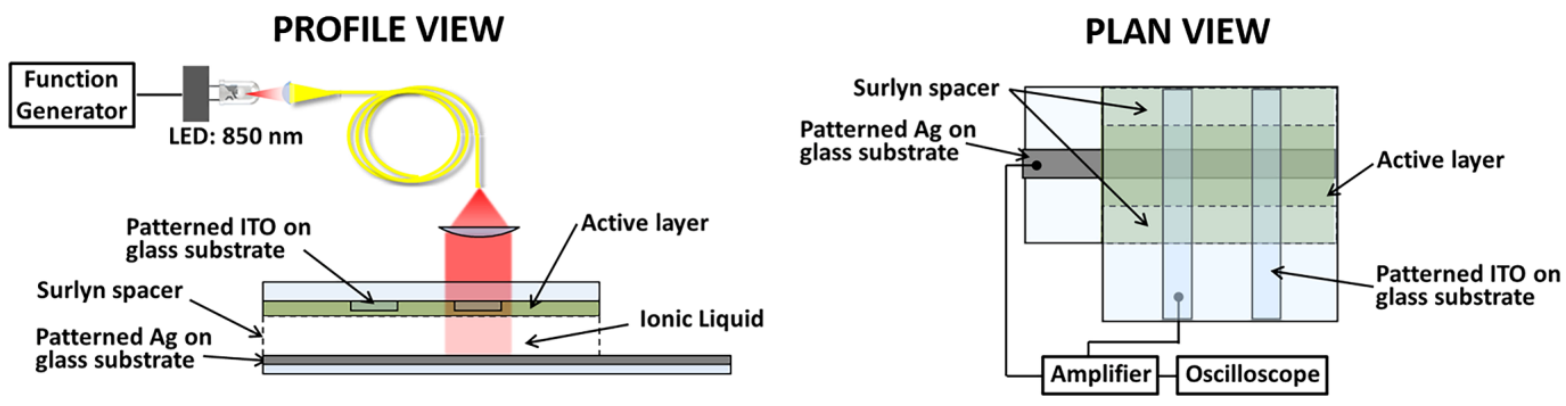

Figure S1: Structure of a completed IL-MISM device. The optical and electronic configurations for transient photocurrent measurement are depicted in the profile and plan views, respectively. 
The electrical connections for the device measurements of: (1) the photocurrent waveform resulting from SnNPc excitation, and (2) the wavelength-dependent photocurrent response (action spectra) are described in the main article. The following describes the optical setups for both measurements:

(1) Light from an LED $\left(\lambda_{\max }=850 \mathrm{~nm}\right)$ was directed onto a collimator via an optical fiber, resulting in a $7 \mathrm{~mm}$ homogeneous broad beam, which was modulated as a square-wave light signal by a function generator (Tektronix AFG320). The light power was adjusted before each experiment by a home-built driver unit (circuit diagram available upon request), and monitored by a silicon photodiode (FID08T13TX) calibrated by an optical power meter (ADCMT 8230E). In all cases, a light power $P_{\text {incident }} \approx 1.1 \mathrm{mWcm}^{-2}$ was used and the responsivity was calculated based on a device area $\approx 0.14 \mathrm{~cm}^{2}$ (ITO width $\times$ beam diameter).

(2) The monochromated light for the action spectra was homogenized and focused to a spot of diameter $2 \mathrm{~mm}$ using a lens array, as described in [2]. In this constellation, the maximum light power was $2.3 \mu \mathrm{W}$, and the light power spectrum was measured using calibrated Si and $\mathrm{Ge}$ photodiodes. The wavelength dependence of the light power and device photocurrent spectra were recorded using a home-written LabVIEW program, which allows multiple scans in forward and reverse direction at a minimal wavelength step of 0.1 $\mathrm{nm}$. In order to ensure signal stabilization on the lock-in amplifier, a time step of at least 2 $s$ was used. 
MOLECULAR STRUCTURE \& PACKING

Additional data for SnNPc:

\begin{tabular}{|c|c|c|}
\hline Formula & \multicolumn{2}{|c|}{$\mathrm{C}_{48} \mathrm{H}_{24} \mathrm{~N}_{8} \mathrm{Sn}$} \\
\hline Formula weight $/ \mathrm{g} \mathrm{mol}^{-1}$ & \multicolumn{2}{|c|}{831.46} \\
\hline Dimension / mm ${ }^{3}$ & \multicolumn{2}{|c|}{$0.10 \times 0.09 \times 0.05$} \\
\hline$T / \mathrm{K}$ & 120 & 300 \\
\hline Crystal system & Monoclinic & Monoclinic \\
\hline Space group & $P 2{ }_{1} / c(\# 14)$ & $P 2_{1} / c(\# 14)$ \\
\hline$a / \AA$ & $15.880(4)$ & 15.936(3) \\
\hline$b / \AA$ & $15.715(4)$ & 15.797(3) \\
\hline$c / \AA$ & $14.354(4)$ & $14.536(3)$ \\
\hline$\beta /{ }^{\circ}$ & 113.086(3) & $113.069(2)$ \\
\hline$V / \AA^{3}$ & 3295.3(14) & 3366.7(12) \\
\hline$Z$ & 4 & 4 \\
\hline$D_{\text {calc }} / \mathrm{g} \mathrm{cm}^{-3}$ & 1.676 & 1.640 \\
\hline$\mu(\mathrm{Mo} \mathrm{K} \alpha) / \mathrm{cm}^{-1}$ & 8.294 & 8.118 \\
\hline$F(000)$ & 1672.00 & 1672.00 \\
\hline $2 \theta_{\max } /^{\circ}$ & 55.1 & 55.0 \\
\hline Reflections collected & 26187 & 26533 \\
\hline Unique reflections ( $\left.R_{\text {int }}\right)$ & 7571 (0.0299) & $7683(0.0374)$ \\
\hline Number of parameters & 514 & 514 \\
\hline Final $R_{1}[I>2 \sigma(I)]^{[\mathrm{a}]}$ & 0.0416 & 0.0475 \\
\hline$w R_{2}^{[\mathrm{b}]}$ & 0.0902 & 0.1120 \\
\hline Goodness of fit & 1.094 & 1.079 \\
\hline \multicolumn{3}{|l|}{ [a] $R_{1}=\Sigma|| F_{\mathrm{o}}|-| F_{\mathrm{c}}|| / \Sigma\left|F_{\mathrm{o}}\right|$} \\
\hline [b] $w R_{2}=\left[\Sigma\left\{w\left(F_{0}^{2}-F_{c}^{2}\right)^{2}\right.\right.$ & $\left.w\left(F_{0}^{2}\right)^{2}\right]^{1 / 2}$ & \\
\hline
\end{tabular}


Table S2: Selected bond distances and inter-planar angles.

$$
120 \mathrm{~K}\left(-153^{\circ} \mathrm{C}\right) \quad 300 \mathrm{~K}\left(27^{\circ} \mathrm{C}\right)
$$

\begin{tabular}{lll}
\hline Bond distances / $\AA$ & \\
\hline Sn1-N1 & $2.248(2)$ & $2.254(3)$ \\
Sn1-N3 & $2.257(3)$ & $2.262(3)$ \\
Sn1-N5 & $2.246(3)$ & $2.251(4)$ \\
Sn1-N7 & $2.245(2)$ & $2.251(3)$
\end{tabular}

Inter-planar angles vs NPc core plane $^{\mathrm{a}} /^{\circ}$

\begin{tabular}{lcc}
\hline C2 to C11 plane & 6.73 & 5.96 \\
C14 to C23 plane & & 2.47 \\
C26 to C35 plane & 2.53 & 6.97 \\
C38 to C47 plane & 7.76 & 4.81 \\
\hline
\end{tabular}

${ }^{\text {a}}$ Least-squares mean plane of N1, N3, N5 and N7.

${ }^{\text {b} L e a s t-s q u a r e s ~ m e a n ~ p l a n e s ~ o f ~ n a p h t h a l e n e ~ c a r b o n ~ a t o m s . ~}$

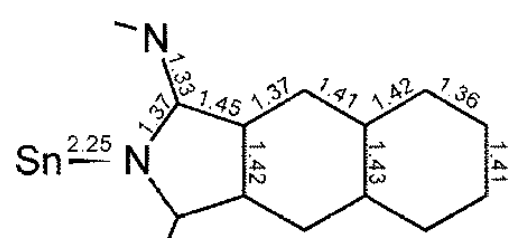

Figure S2: Average distances of the chemically distinct classes of bonds $(\AA)$ in SnNPc at $-153^{\circ} \mathrm{C}$. 


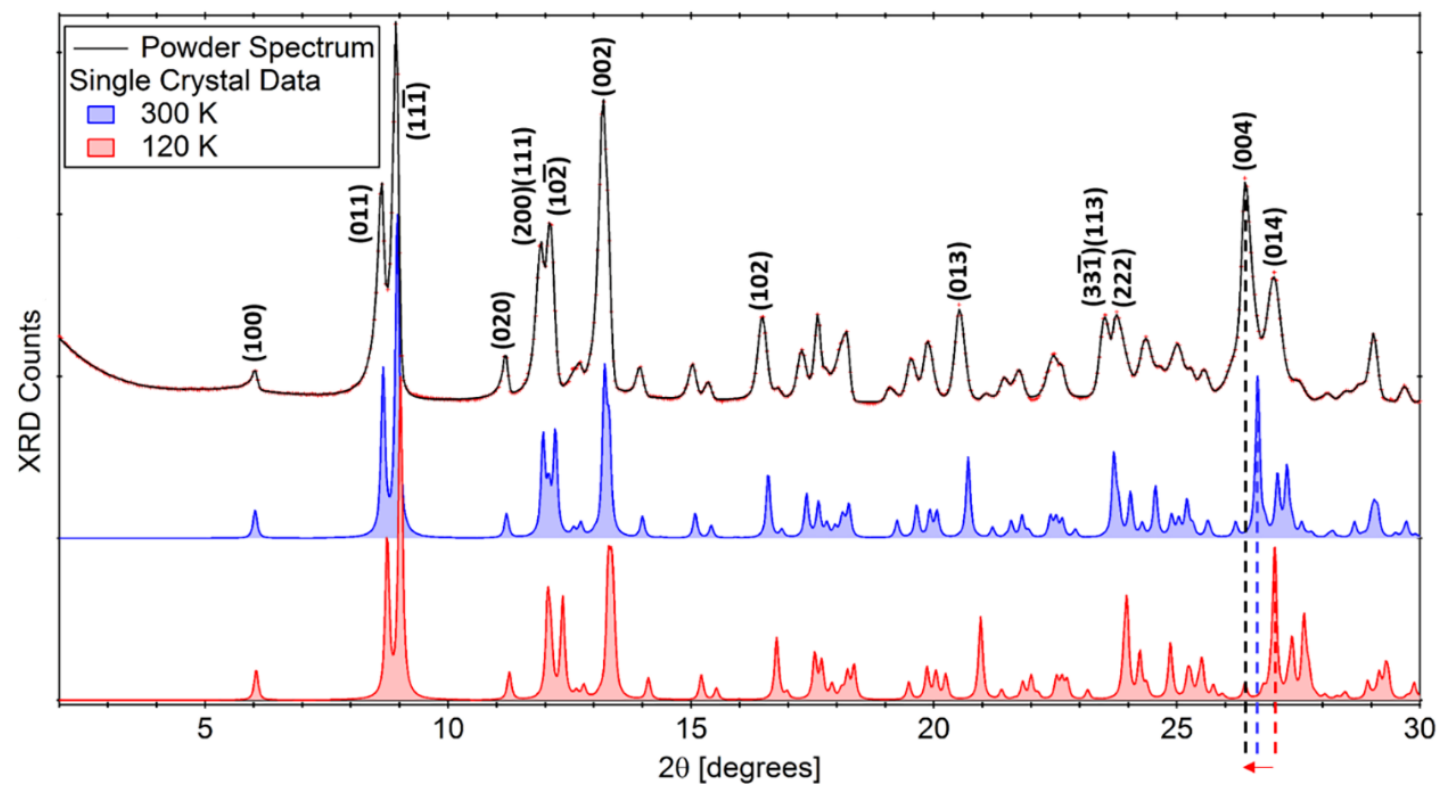

Figure S3: Powder XRD of commercial SnNPc (black line represents the fitted data, and red markers indicate the raw data), compared to simulated data from single crystal analysis at $-153^{\circ} \mathrm{C}(120 \mathrm{~K})$ and $27^{\circ} \mathrm{C}(300 \mathrm{~K})$. Major peaks are indexed based on the single crystal data. Red arrow indicates the shift in the 004 peak observed, as discussed in the main article.
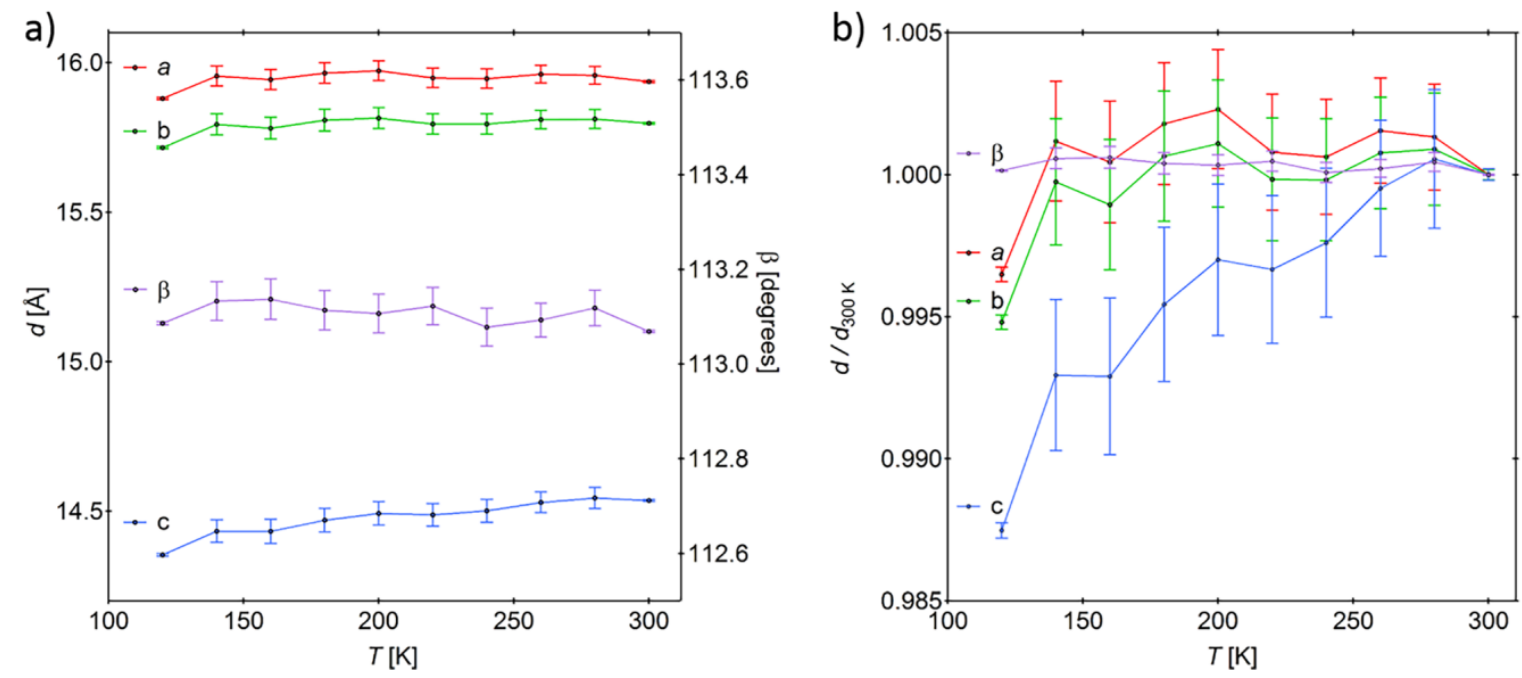

Figure S4: Change in unit cell parameters for SnNPc crystals as a function of temperature between $-153^{\circ} \mathrm{C}(120 \mathrm{~K})$ and $27^{\circ} \mathrm{C}(300 \mathrm{~K}):$ a) absolute values; b) change relative to parameters at $27^{\circ} \mathrm{C}$. 
Additional data for VONPc:

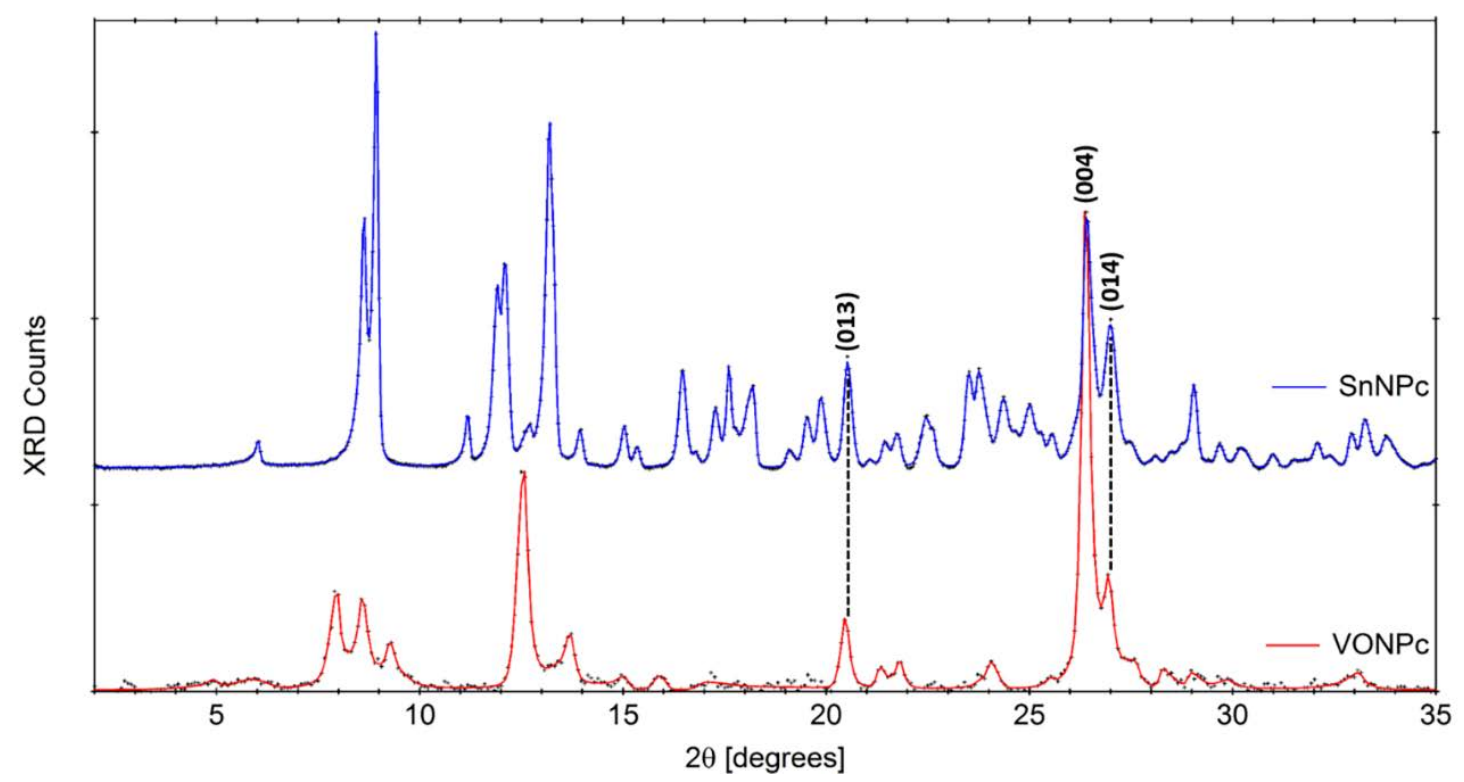

Figure S5: Powder XRD of VONPc, compared to that of SnNPc (solid lines represents the fitted data, and black markers indicate the raw data). Common peaks are highlighted, and indexed based on the single crystal data for SnNPc. 


\section{THIN FILM CHARACTERIZATION}

\section{As deposited films of SnNPc:}
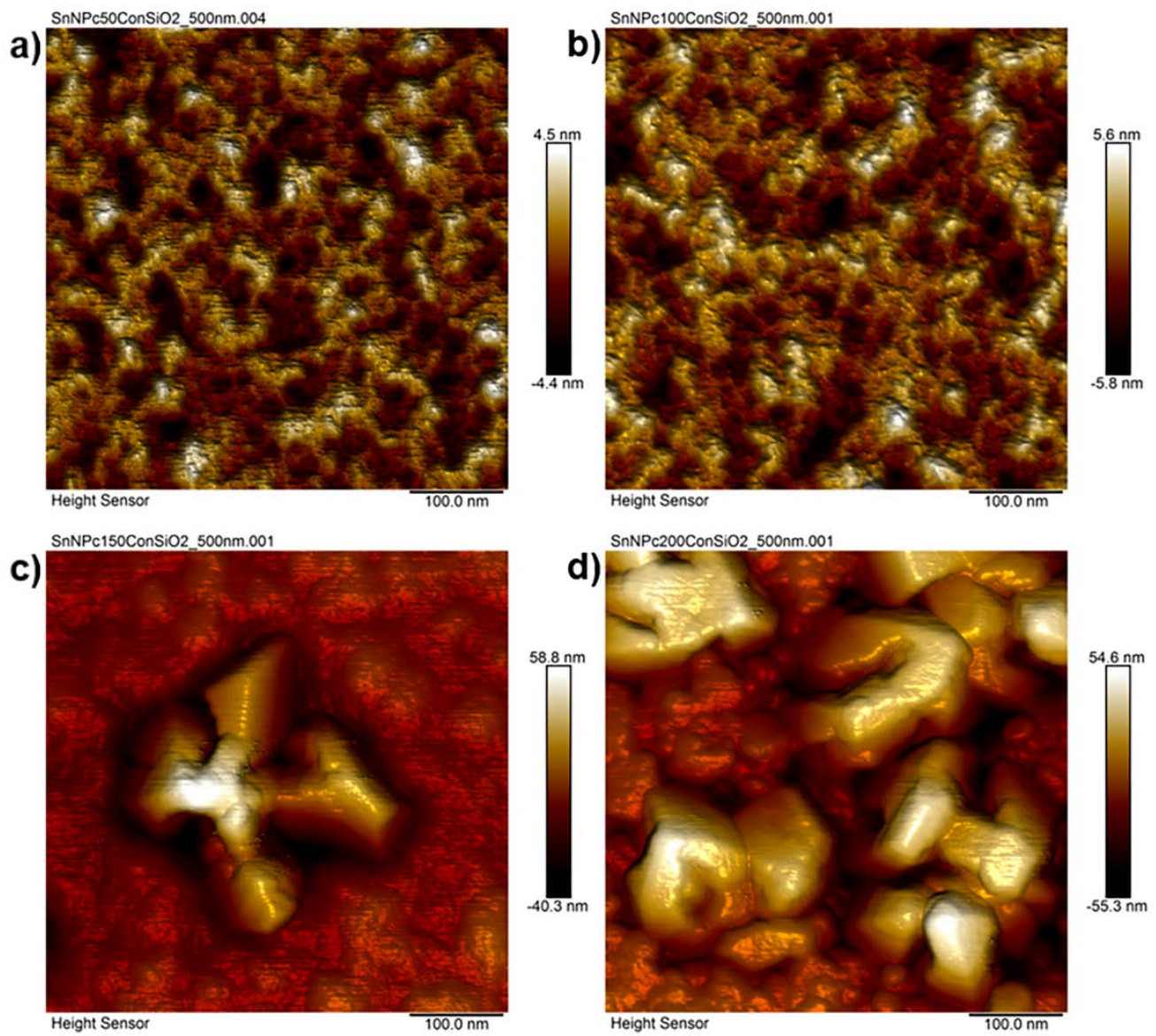

Figure S6: AFM images of $\operatorname{SnNPc}\left(d=100 \mathrm{~nm}\right.$, rate $\left.=0.1 \mathrm{As}^{-1}\right)$ deposited on $\mathrm{SiO}_{2}$ at substrate temperatures of (a) $50^{\circ} \mathrm{C}$, (b) $100^{\circ} \mathrm{C}$, (c) $150^{\circ} \mathrm{C}$ and (d) $200^{\circ} \mathrm{C}$.

The AFM image representing the deposition at $150^{\circ} \mathrm{C}$ shows an isolated crystallite occasionally observed over an otherwise amorphous surface, which was similar to that observed at $50^{\circ} \mathrm{C}$ and $100^{\circ} \mathrm{C}$. Such features covered about $5-10 \%$ of the surface on $\mathrm{SiO}_{2}$, and increased in frequency with the roughness of the underlying substrate. 


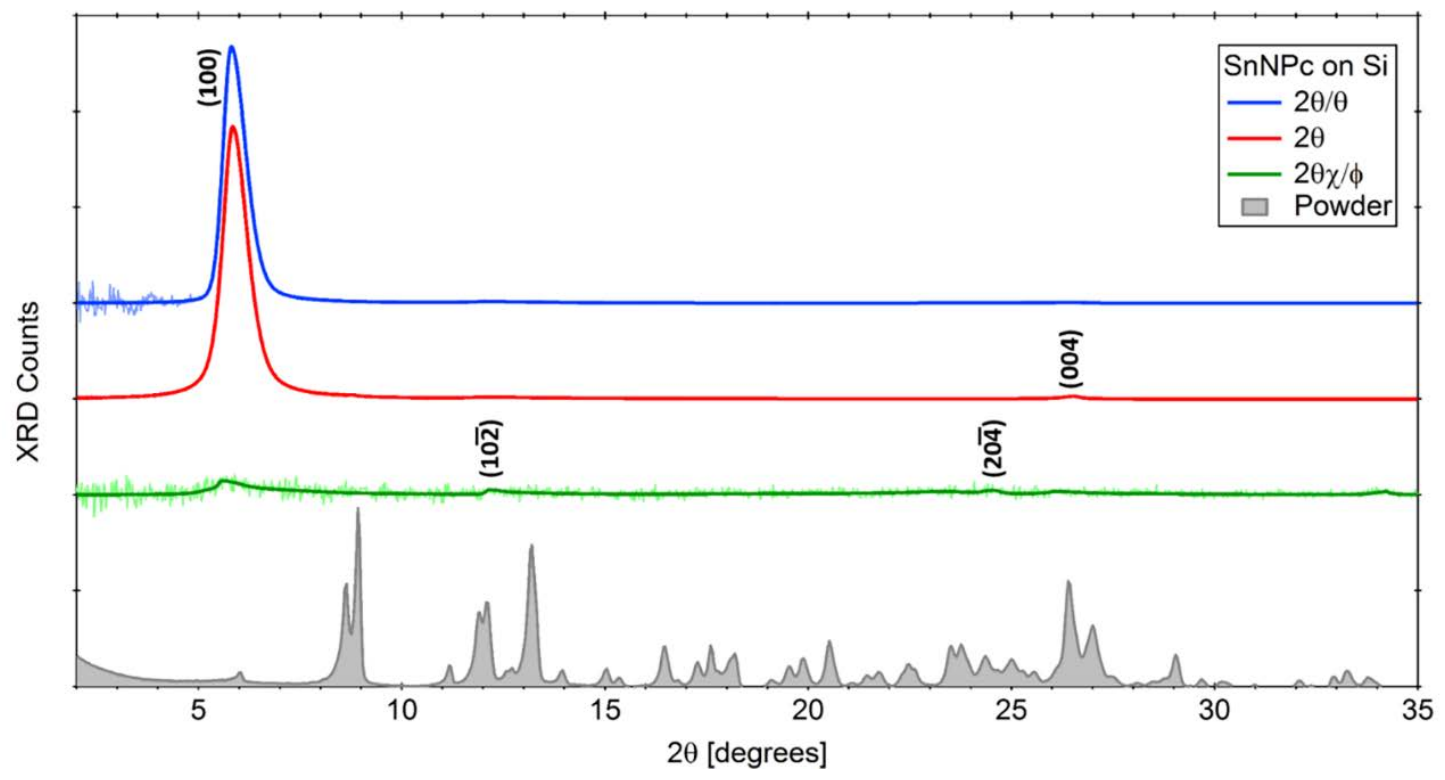

Figure S7: Thin film XRD measured in different geometries for a film of SnNPc $\left(d=100 \mathrm{~nm}\right.$, rate $\left.=0.1 \AA \mathrm{s}^{-1}\right)$ deposited on Si wafer at a substrate temperature of $200^{\circ} \mathrm{C}$. In all cases, the bold line represents the fitted data, while the thin line represents the (baseline subtracted) raw data.

While the peaks corresponding to the 102 and 204 planes weakly observed in the in-plane scan are nearly orthogonal to the 100 plane, the fact that 100 plane is also observed in the inplane scan, and a weak diffraction corresponding to the 004 plane is observed in the out-ofplane (more visible on $\mathrm{SiO}_{2}$ substrates, c.f. Fig. 2a) and asymmetric scans suggests some biaxial orientation in the film at $200^{\circ} \mathrm{C}$. 


\section{Solvent annealing of SnNPc:}

The resolved packing structure of SnNPc is similar to that of Phase I TiOPc,[3] and in the amorphous state, the absorption profile is qualitatively the same as that of TiOPc (amorphous), though shifted due to benzanulation. Distinct crystalline phases for TiOPc have been induced from amorphous thin films by solvent vapor annealing (Phase I (xylene); Phase II (acetone or tetrahydrofuran); Phase Y (chlorobenzene:water 10:1)), which have been indexed to resolved crystalline structures (Phase I \& II),[3] or from Rietveld refinement of powder data (Phase Y)[4] and which show distinct absorption profiles stretching into the NIR. In an effort to access such polymorphism from the "shuttlecock" NPcs, solvent vapor annealing was performed on amorphous films of SnNPc and VONPc (c.f. Fig S13), screening various solvents and solvent mixtures. 


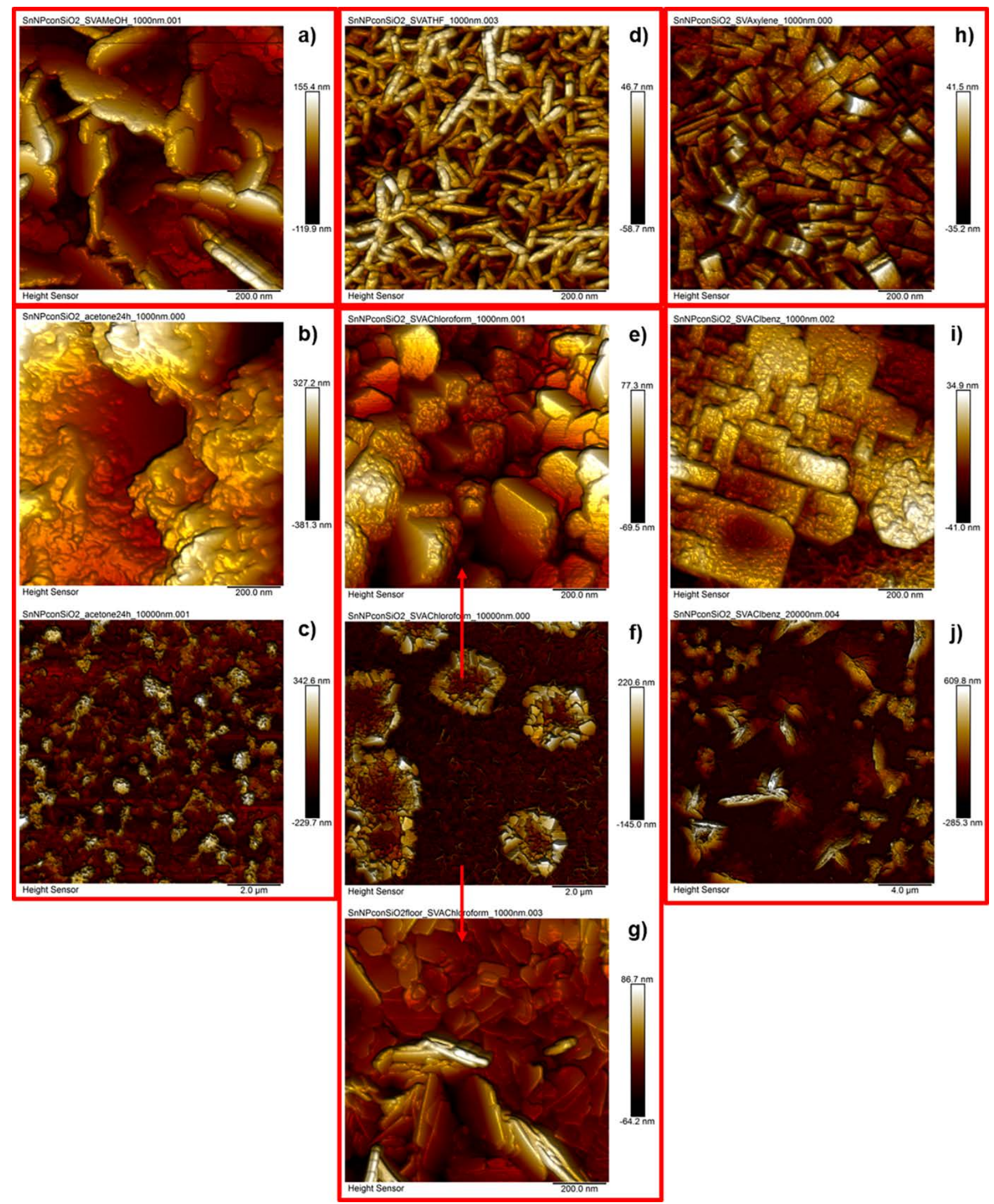

Figure S8: AFM images of amorphous SnNPc films following solvent vapor annealing in different solvents: (a) $\mathrm{MeOH}$; $(\mathrm{b}-\mathrm{c})$ acetone; (d) THF; $(\mathrm{e}-\mathrm{g})$ chloroform; (h) xylene; $(\mathrm{I}-\mathrm{j})$ chlorobenzene:water (10:1). 
In all cases of SVA, a significant increase in crystallinity was observed. Figure S8 shows the AFM images for each of the SVA films. In the case of $\mathrm{MeOH}$, THF and xylene, a continuous uniform crystalline structure was observed, though the morphologies of the crystallites were distinct, forming flakes, rods and blocks, respectively. In the case of acetone, the morphology resembled that of the amorphous films, but with a distinct increase in roughness, caused by large ill-defined crystallites. In the case of chloroform, two distinct phases were observed over the surface, with rings of block-shaped crystallites decorating a surface of dominated by flakes. In the case of chlorobenzene:water, extremely large block-shaped crystals were observed, randomly distributed over an otherwise smooth surface, which seemed to correspond to the underlying substrate, suggesting the film reorganized, possibly due to a phase separation of the orthogonal solvent mixture on the substrate surface.

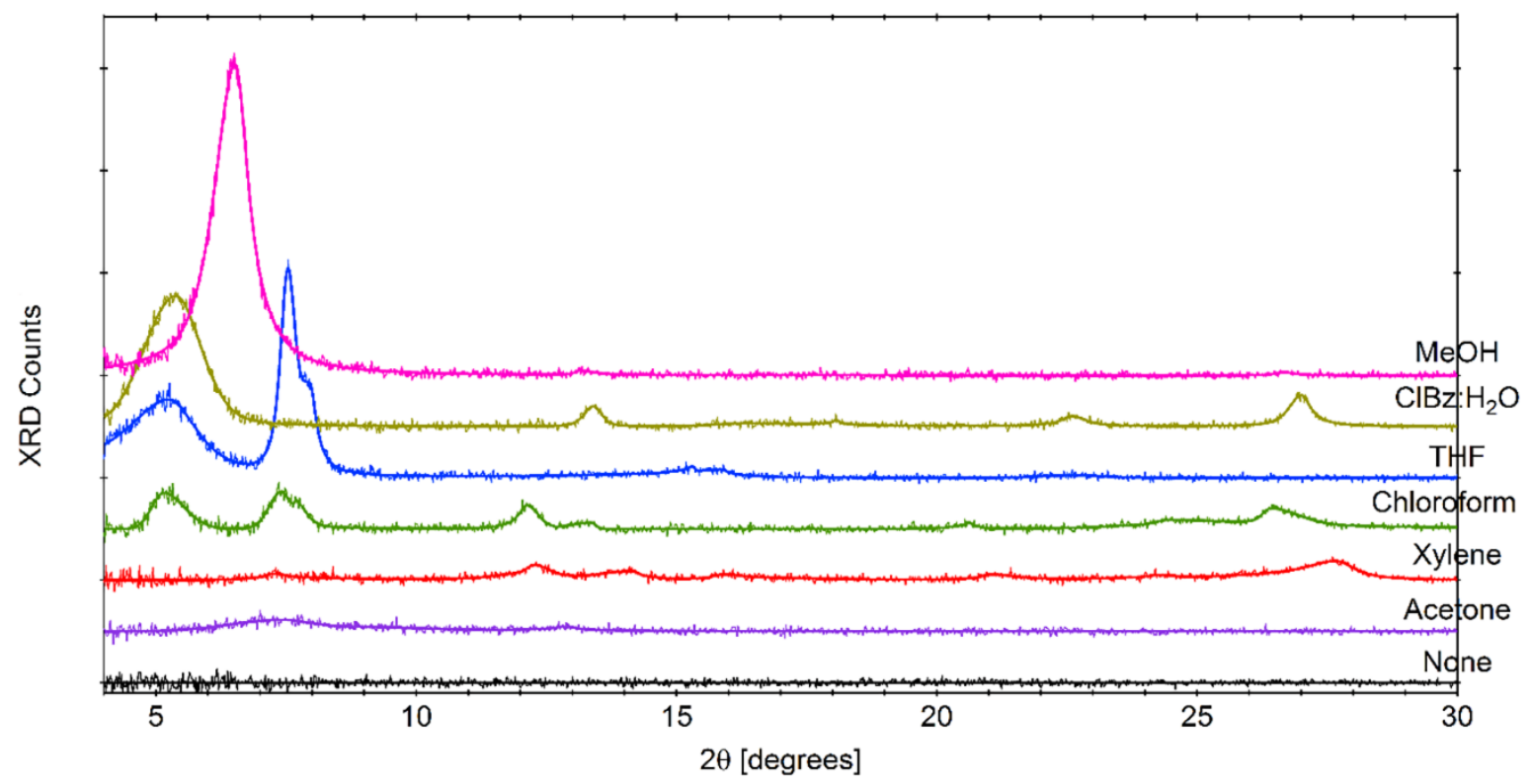

Figure S9: Thin film XRD of initially amorphous films of SnNPc $\left(d=50 \mathrm{~nm}\right.$, rate $\left.=0.5 \AA^{-1}\right)$ deposited on $\mathrm{SiO}_{2}$ following solvent vapor annealing (data offset for clarity).

Figure S9 shows the thin film XRD data for the solvent annealed films. As discussed in the main article, treatment with $\mathrm{MeOH}$ results in a crystalline phase identical to the high temperature deposition of SnNPc. Following treatment with THF for $4 \mathrm{~h}$, the XRD pattern showed a strong split peak at $\sim 7.5^{\circ}$ with an additional small peak around $15^{\circ}$. These peaks do not correspond to any peaks from the single crystal data recorded for SnNPc, but the peak at $\sim 7.5^{\circ}$ is commonly observed for chloroform ( $4 \mathrm{~h}$ ), and weakly for acetone $(24 \mathrm{~h})$ treated samples, and in all these cases, the absorption spectra show a decrease in the dominant peak of the Q-band peak for the amorphous film at $860 \mathrm{~nm}$, with associated broadening, as shown in Figure S10. However, at least in the case of chloroform, a mixed phase is likely, since a new peak is observed in its absorption spectrum around $1200 \mathrm{~nm}$, as well as an increased visible component, both of which also characterize the spectrum of the chlorobenzene:water treated film (which is known to induce Phase $Y$ in TiOPc). [5,6] This conclusion is supported by the biphasic structure observed under AFM, as shown in Figure $\mathrm{S} 8$. 

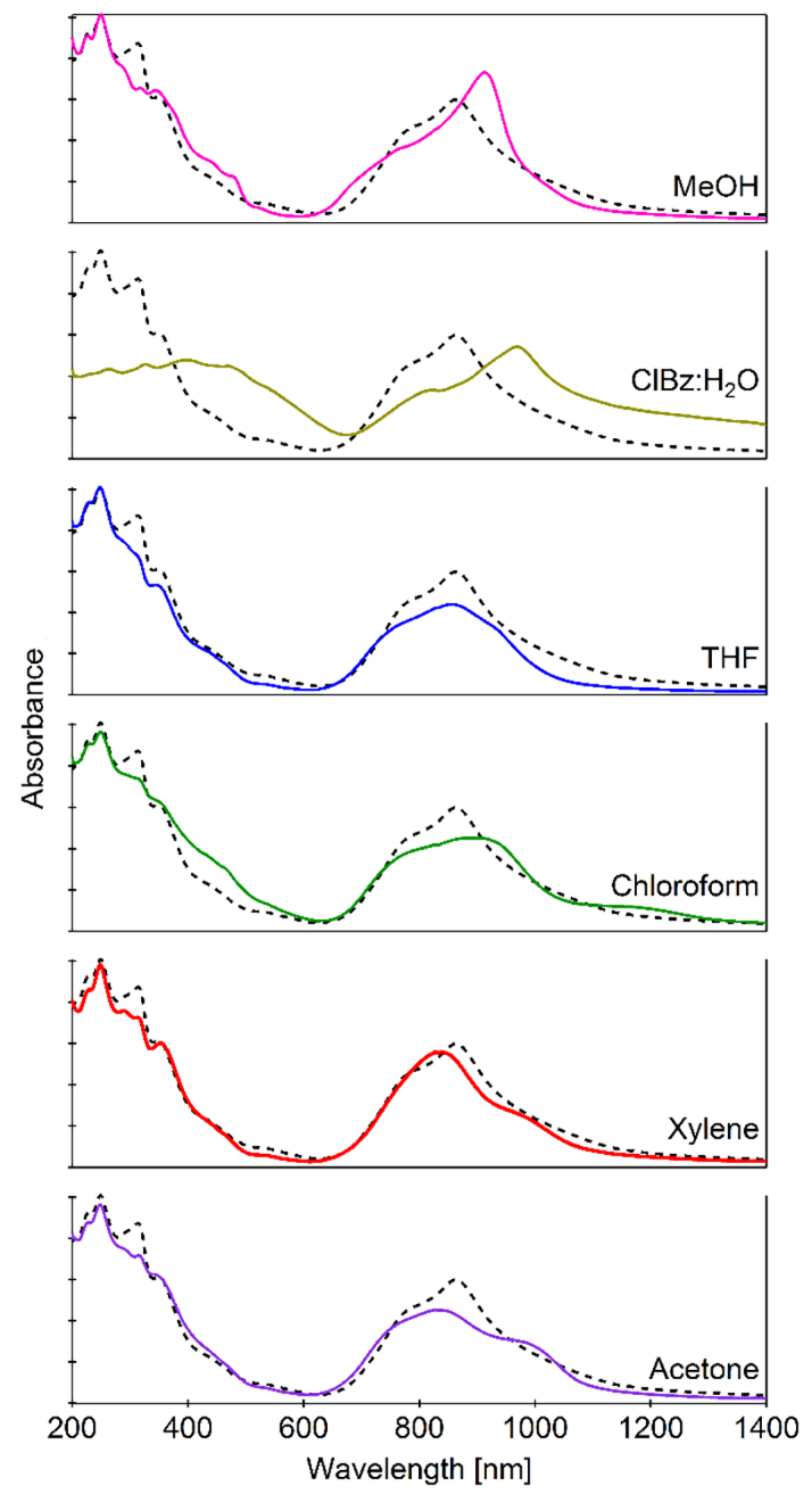

Figure S10: Thin film absorption spectra of amorphous films of SnNPc ( $d=50 \mathrm{~nm}$, rate $\left.=0.5 \AA \mathrm{s}^{-1}\right)$ (broken lines) deposited on quartz substrates, following solvent vapor annealing in various solvents (solid lines).

In the case of xylene, which was reported to induce Phase I for TiOPc, $[5,6]$ the XRD pattern is characterized by the absence of low angle peaks, but shows a clear reflection at $27.7^{\circ}$. The absorption spectra for this film is distinct in that the major Q-band is blue-shifted $\left(\lambda_{\max }=815\right.$ $\mathrm{nm}$ ) compared to the amorphous film. While a reflection at $28^{\circ}$ might correspond to the close interplanar distance (-212) in Phase II of TiOPc,[3] the trend in the absorption profile seems distinct.

While the absorption spectrum and thin film XRD of the $\mathrm{MeOH}$ treated films are analogous to the Phase I standing arrangement induced by elevated temperature deposition of SnNPc, and the spectral changes induced by chlorobenzene:water are similar to those reported for Phase $Y$ in TiOPc, the identity of the other SVA films remain unclear. Since no further information could be gained by adopting different scanning geometries for XRD, we await single crystal data of other polymorphs of SnNPc in order to correctly assign these distinct crystalline forms. 


\section{As deposited films of VONPc:}
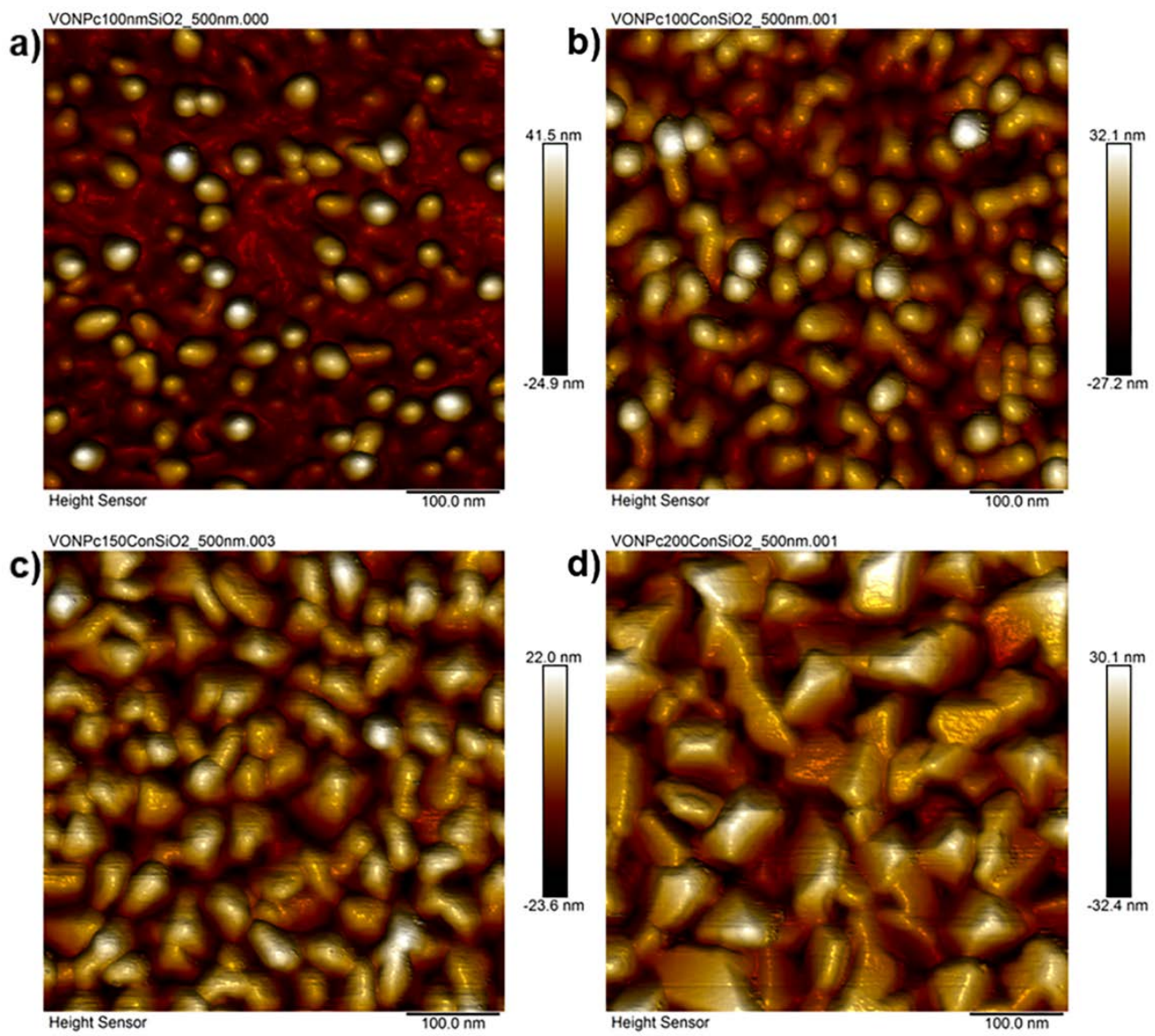

Figure S11: AFM of VONPc $(d=80-100 \mathrm{~nm})$ deposited on $\mathrm{SiO}_{2}$ at substrate temperatures of (a) $50^{\circ} \mathrm{C},(\mathrm{b}) 100^{\circ} \mathrm{C}$, (c) $150^{\circ} \mathrm{C}$ and (d) $200^{\circ} \mathrm{C}$.
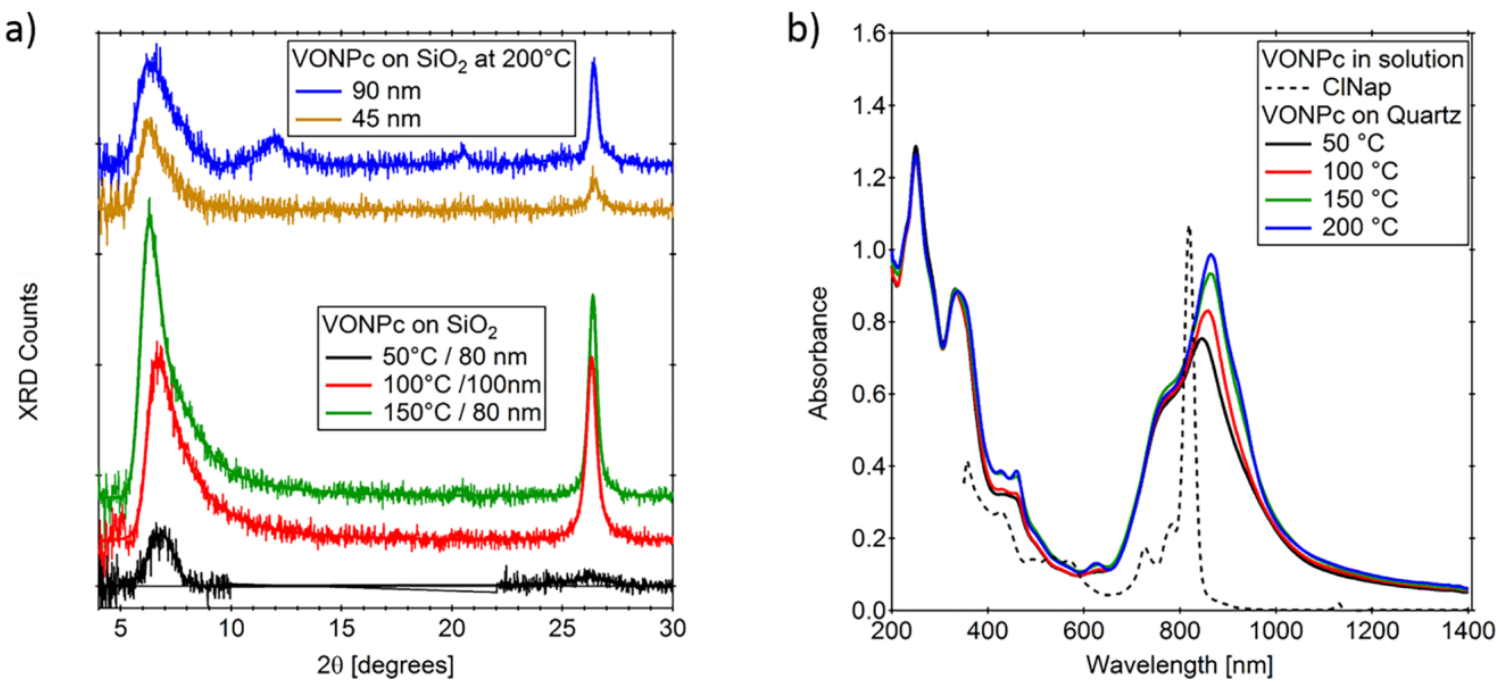

Figure S12: Characterization of thin films of VONPc $(d=80-100 \mathrm{~nm})$ deposited at various substrate temperatures: a) thin film XRD on $\mathrm{SiO}_{2}$ substrates (data offset for clarity). Also shown is the difference in relative peak heights for thin and thick films deposited at $200^{\circ} \mathrm{C}$; b) thin film absorption spectra on quartz substrates, compared to the solution spectrum (arbitrary scale) of VONPc, measured in 1-chloronaphthalene (CINap). For comparison, the spectra are adjusted for thickness, and show a common overlap in the peak at $250 \mathrm{~nm}$, as for SnNPc. 
Solvent annealing of VONPc:

a)

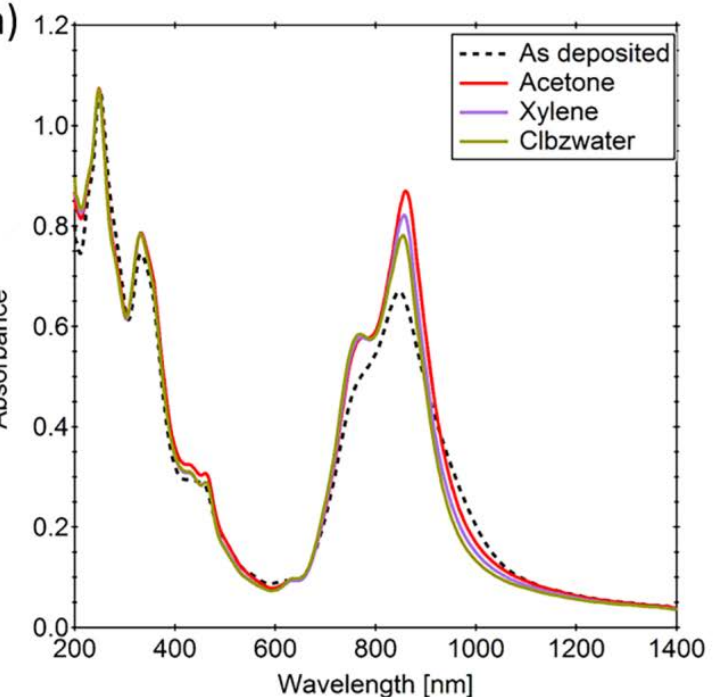

b)

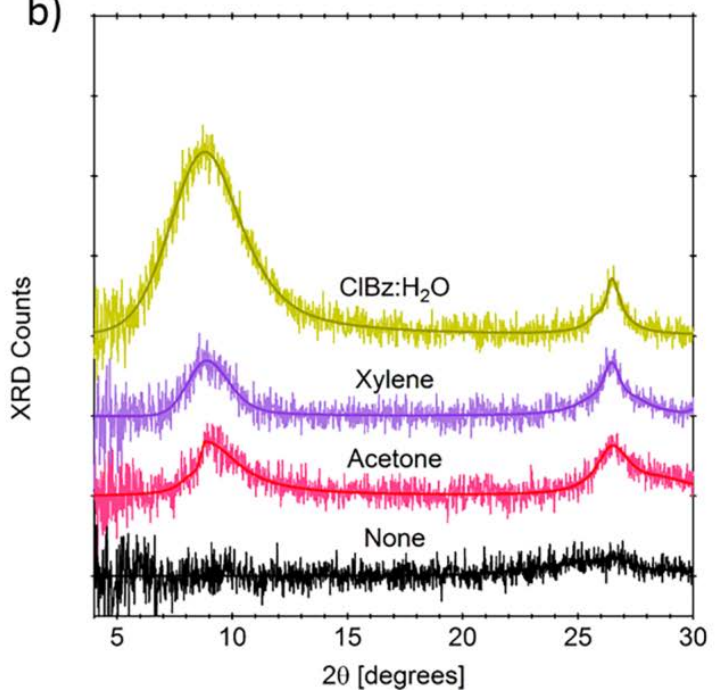

Figure S13: Characterization of thin films of VONPc $(d=80 \mathrm{~nm})$ following solvent vapor annealing: a) thin film absorption spectra on quartz substrates; b) thin film XRD on quartz substrates (data offset for clarity). 


\section{Templated films of SnNPc:}

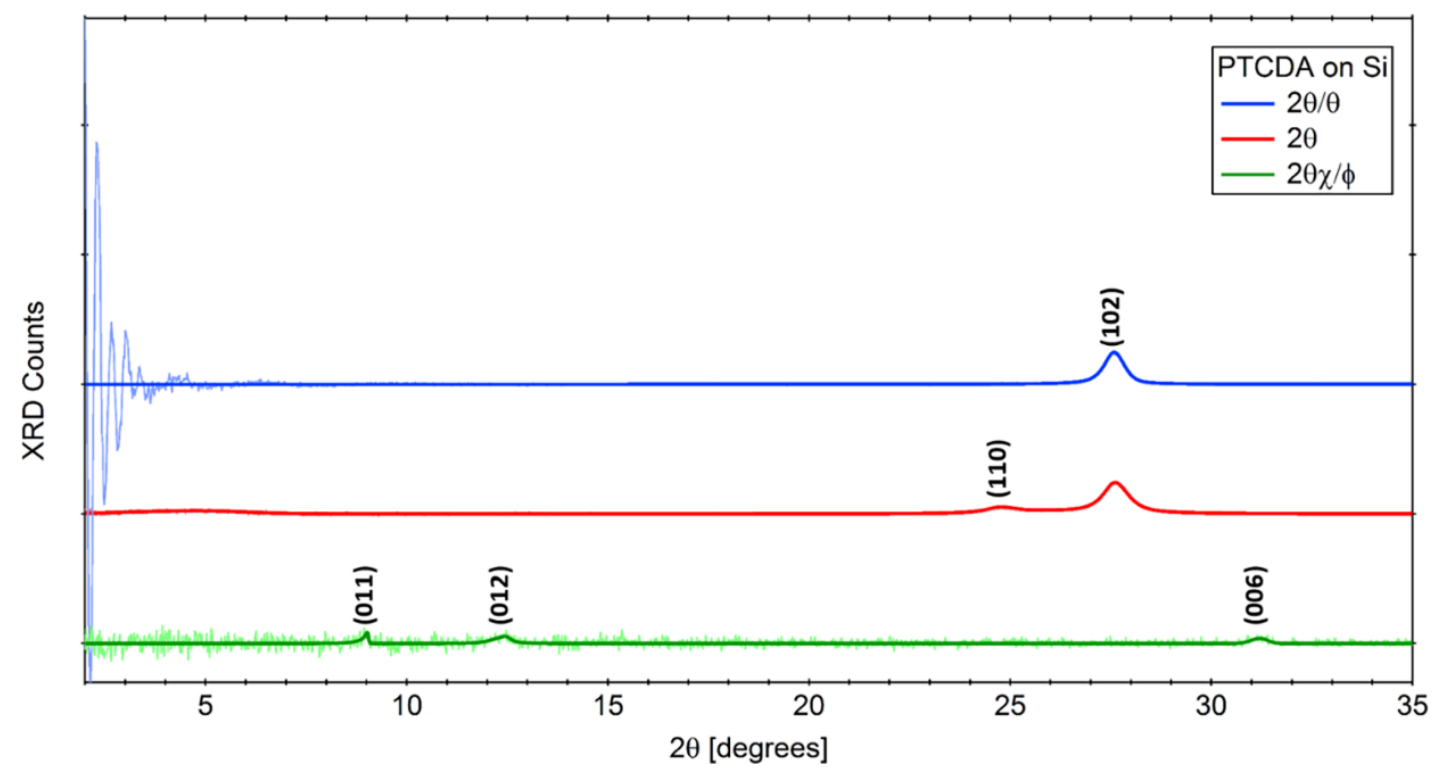

Figure S14: Thin film XRD measured in different geometries for a film of PTCDA $\left(d=20 \mathrm{~nm}\right.$, rate $\left.=1.0 \AA \mathrm{s}^{-1}\right)$ on Si wafer. In all cases, the bold line corresponds to the fitted data, while the thin line represents the (baseline subtracted) raw data.

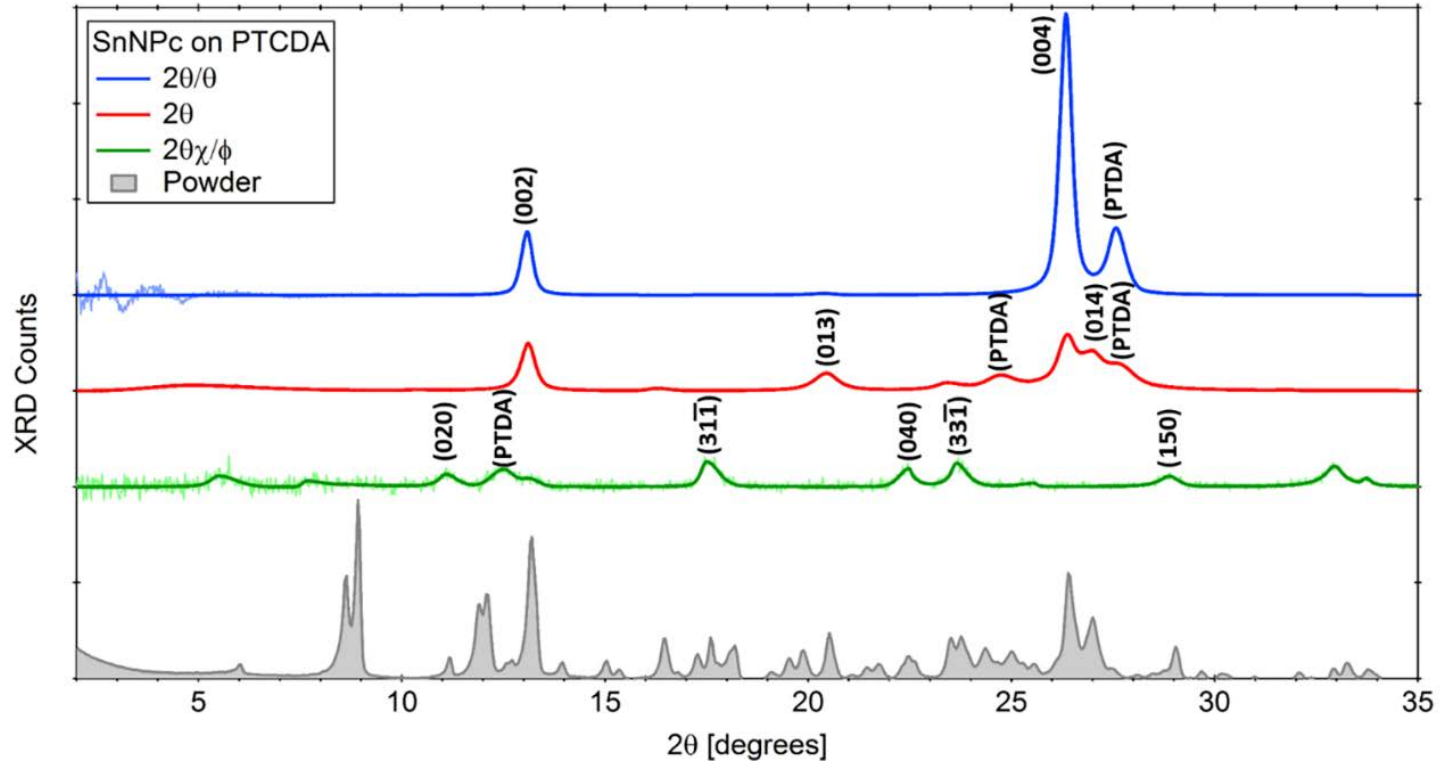

Figure S15: Thin film XRD measured in different geometries for a film of SnNPc ( $d=100 \mathrm{~nm}$, rate $\left.=0.1 \AA \mathrm{s}^{-1}\right)$ deposited on a templating layer of PTCDA $\left(d=20 \mathrm{~nm}\right.$, rate $\left.=1.0 \AA^{-1}\right)$ on Si wafer. In all cases, the bold line corresponds to the fitted data, while the thin line represents the (baseline subtracted) raw data. 

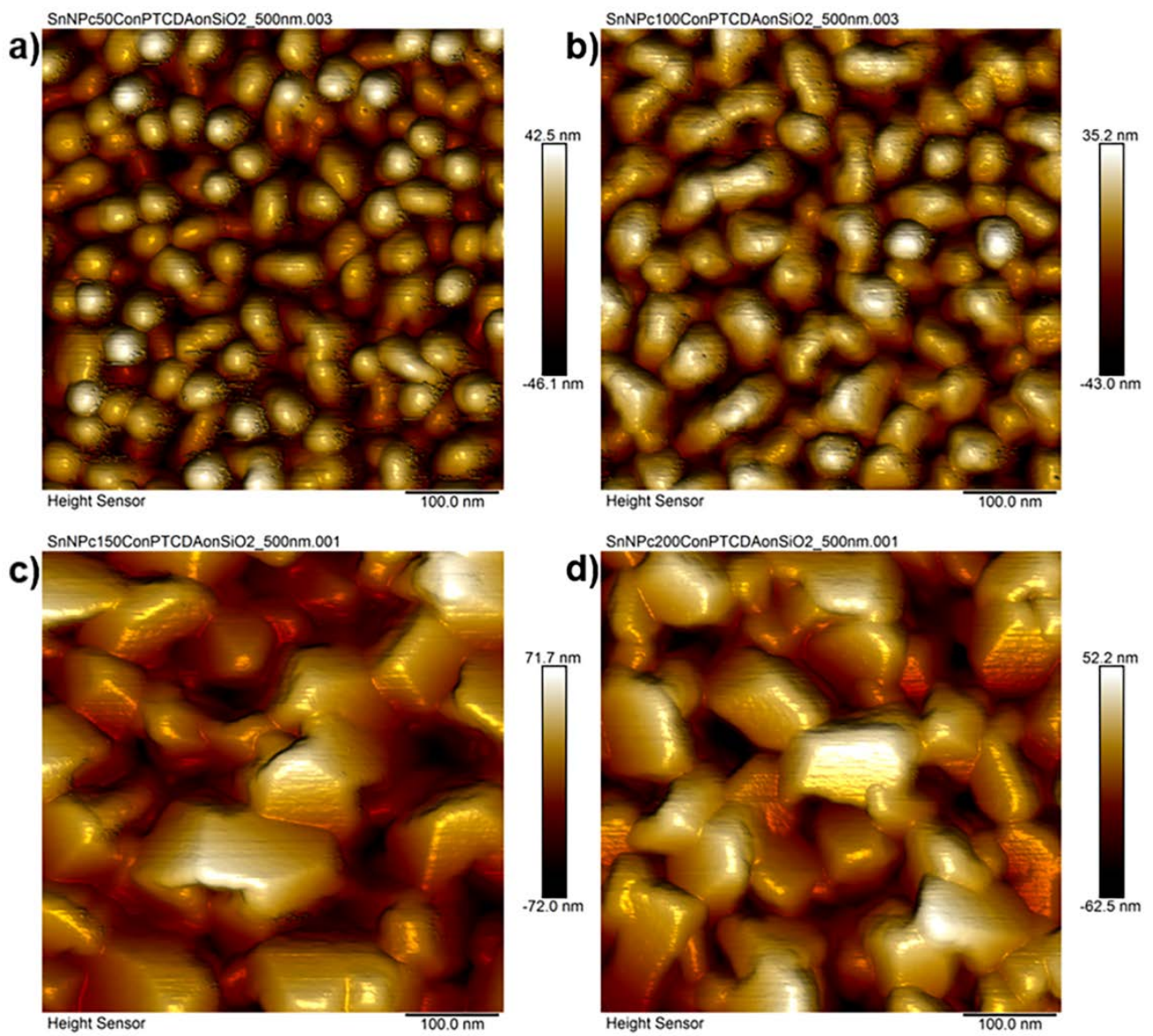

Figure S16: AFM of SnNPc $\left(d=100 \mathrm{~nm}\right.$, rate $\left.=0.1 \mathrm{As}^{-1}\right)$ deposited on a templating layer of PTCDA $(d=20 \mathrm{~nm}$, rate $=1.0 \AA^{-1}$ ) on $\mathrm{SiO}_{2}$ at substrate temperatures of (a) $50^{\circ} \mathrm{C}$, (b) $100^{\circ} \mathrm{C}$, (c) $150^{\circ} \mathrm{C}$ and (d) $200^{\circ} \mathrm{C}$. 


\section{Templated films of VONPc:}

a)

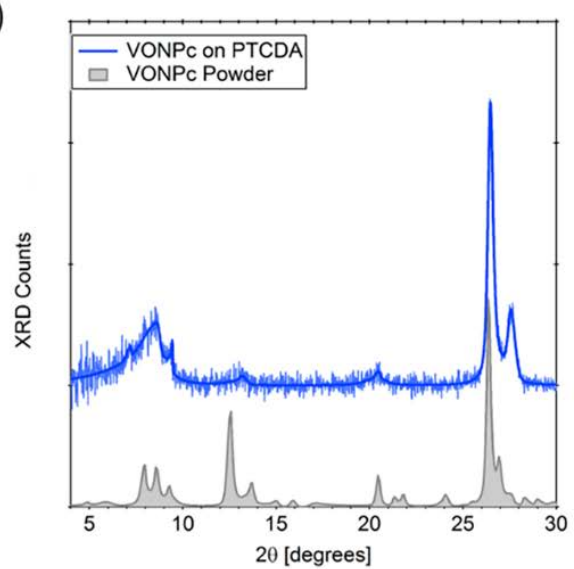

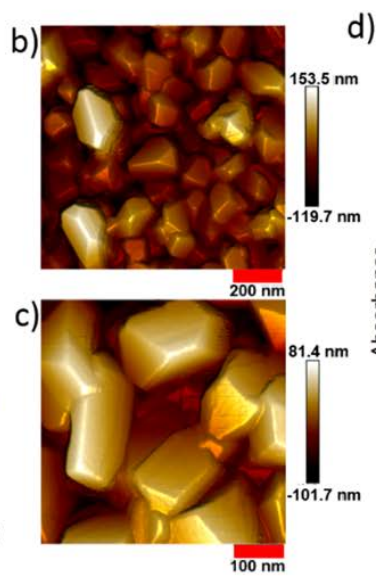

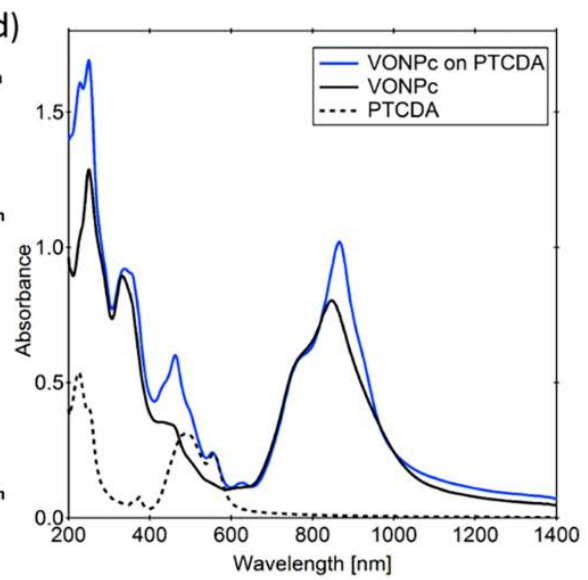

Figure S17: Characterization of a thin film of VONPc $(d=100 \mathrm{~nm})$ grown on a $20 \mathrm{~nm}$ film of PTCDA at $200^{\circ} \mathrm{C}$ : (a) thin film XRD, compared to the powder XRD data (data offset for clarity); (b,c) AFM images of a templated film grown on $\mathrm{SiO}_{2}$, where the red scale bar indicates (b) $200 \mathrm{~nm}$, and (c) $100 \mathrm{~nm}$; d) thin film absorption spectra on quartz substrates of a templated film of VONPc (blue line), compared to an untemplated film grown at $50^{\circ} \mathrm{C}$ (black line) and the templating layer of PTCDA (broken line). 
Versatility of molecular templating:
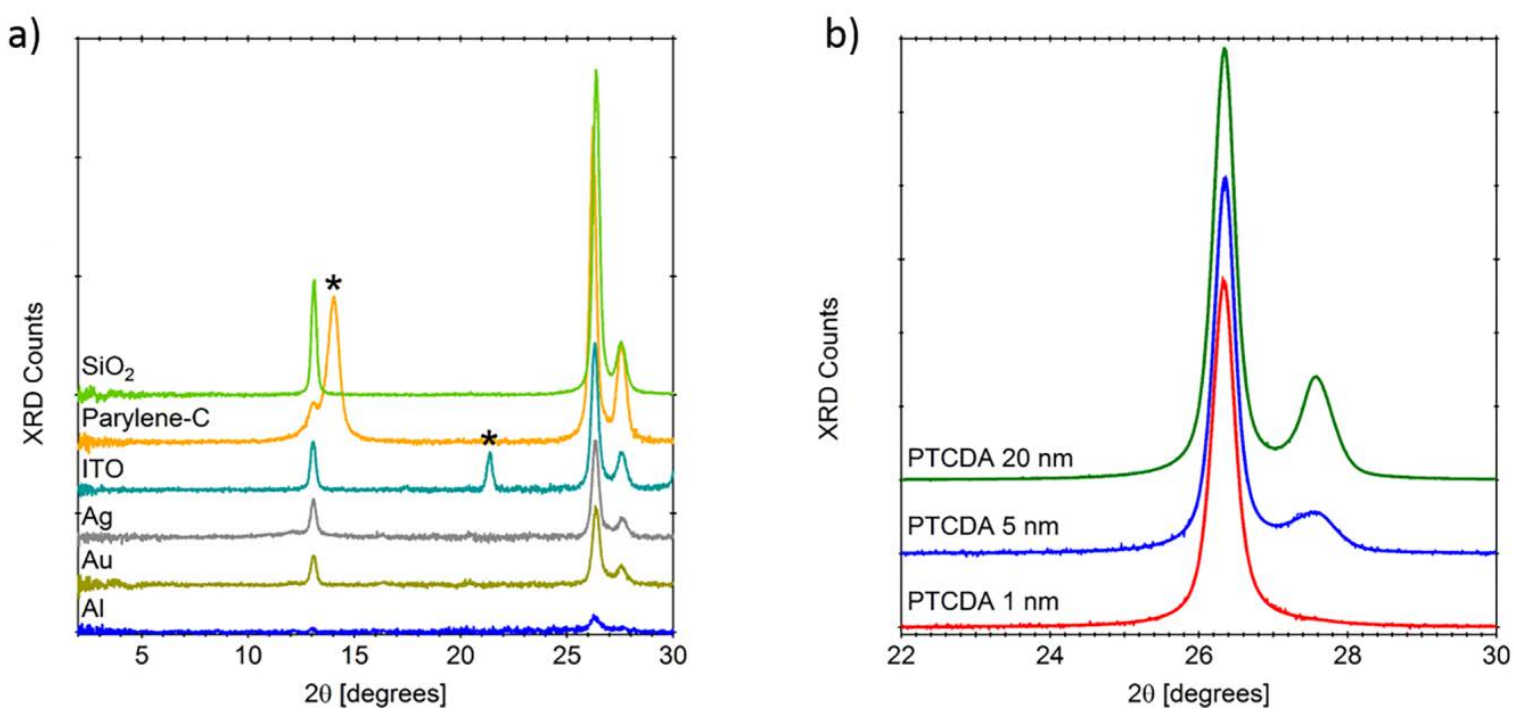

Figure S18: Thin film XRD of SnNPc $\left(d=100 \mathrm{~nm}\right.$, rate $\left.=0.1 \mathrm{As}^{-1}\right)$ on: a) PTCDA $\left(d=20 \mathrm{~nm}\right.$, rate $\left.=1.0 \AA \mathrm{s}^{-1}\right)$ deposited on various substrates at $150^{\circ} \mathrm{C}$ ( ${ }^{*}$ denotes peaks originating from the substrate); b) PTCDA of thicknesses 1,5 and $20 \mathrm{~nm}$, deposited at $1 \mathrm{As}^{-1}$ on $\mathrm{SiO}_{2}$ substrates (data offset for clarity).

While the peak intensity, and position within the range of $26.3^{\circ}$ and $26.4^{\circ}$, varied by XRD, the crystalline features were remarkably consistent by AFM for the inorganic substrates, with block shaped crystals of dimensions $100-200 \mathrm{~nm}$. Since the peak heights of the templated films were anti-correlated with the surface roughness of the underlying substrate (see Table S3), it seems likely that the film templates from the PTCDA microcrystals (size $\sim 30 \mathrm{~nm}, c$.f. Fig. 3b) which decorate the underlying undulations of the substrate, yielding orientations offnormal to the substrate plane, which would be silent in the symmetric $2 \vartheta / \vartheta$ geometry.

\begin{tabular}{cccc}
\hline \multicolumn{5}{c}{ Table S3: Roughness parameters of the substrates, as measured by AFM. } & \\
\hline Substrate & $R_{\mathrm{a}} / \mathrm{nm}$ & $R_{\mathrm{z}} / \mathrm{nm}$ & Average particle size / nm \\
\hline $\mathrm{Al}$ & 15 & 40 & 100 \\
$\mathrm{Au}$ & 4 & 12 & 50 \\
$\mathrm{Ag}$ & 3 & 7 & 50 \\
$\mathrm{ITO}$ & 2 & 4 & 10 \\
Parylene-C & 3 & 7 & N.A. \\
$\mathrm{SiO}_{2}$ & 0.1 & 0.4 & N.A. \\
\hline
\end{tabular}



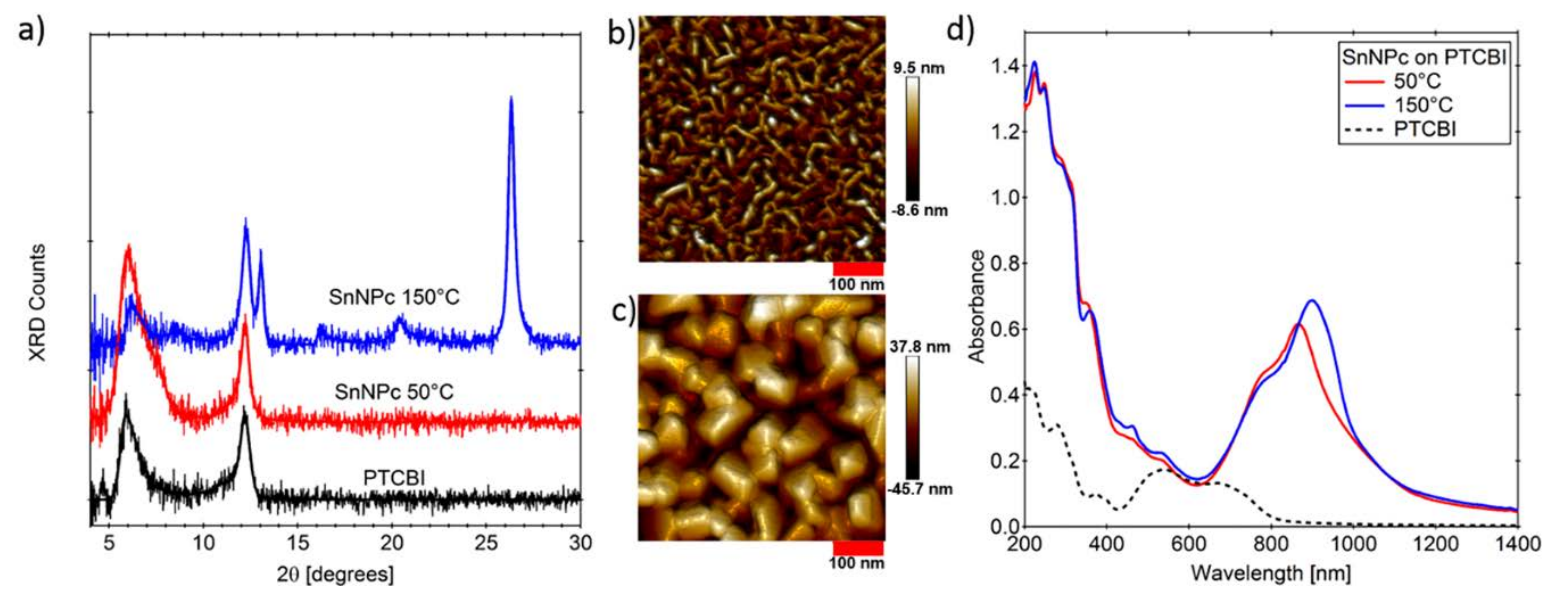

Figure S19: Characterization of thin films of SnNPc $(d=75 \mathrm{~nm})$ grown on a $20 \mathrm{~nm}$ film of PTCBI at various temperatures: (a) thin film XRD on $\mathrm{SiO}_{2}$ substrates (data offset for clarity; (b-c) AFM images of (b) the templating layer of PTCBI, and (c) the templated film of SnNPc grown at a substrate temperature of $150^{\circ} \mathrm{C}$, red scale bars indicate $100 \mathrm{~nm}$; d) Thin film absorption spectra on quartz substrates (solid lines), compared to the thin film spectrum of the templating layer of PTCBI (broken line). 
ANALYSIS OF THE ABSORPTION SPECTRA

\section{Computational analysis:}

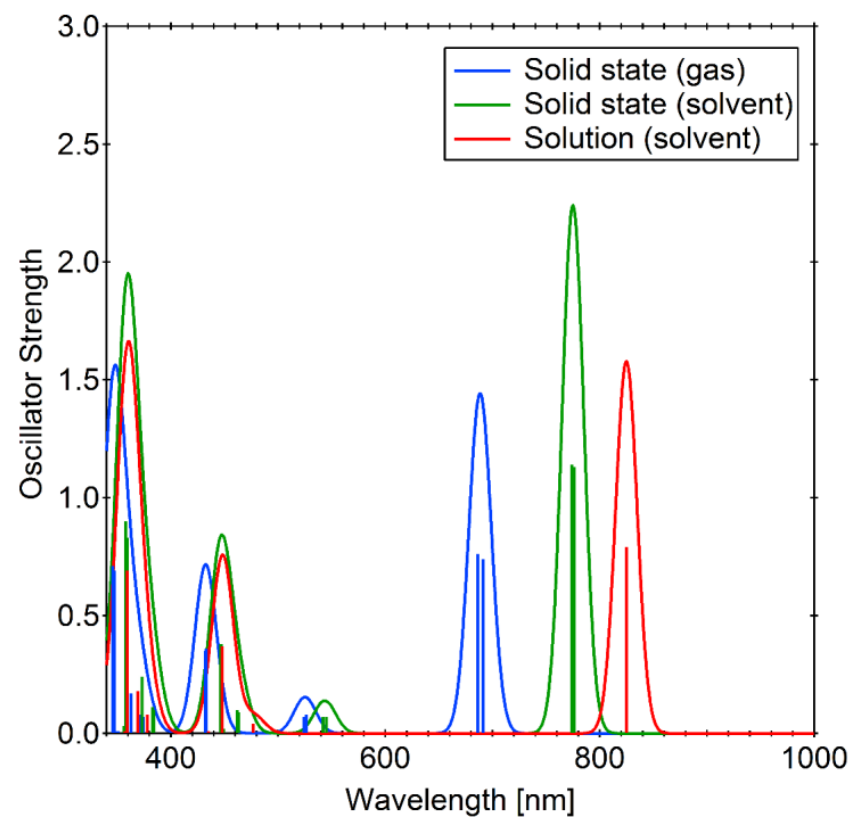

Figure S20: Comparison between the calculated monomer absorption spectra for SnNPc optimized in the solid state, with the spectra computed in the gas phase (blue) or in 1-chloronaphthalene (green), compared to that of the solution optimized structure computed in 1-chloronaphthalene (red). Sticks to zero indicate the energy of the model transitions, showing minimal splitting of the Q-band even when $\mathrm{C}_{4 \mathrm{v}}$ symmetry is broken in the solid state.

a)

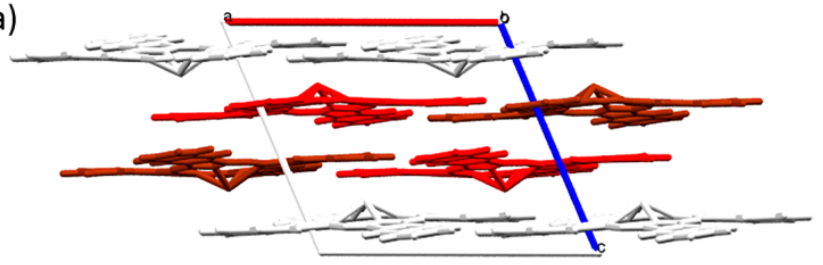

b)

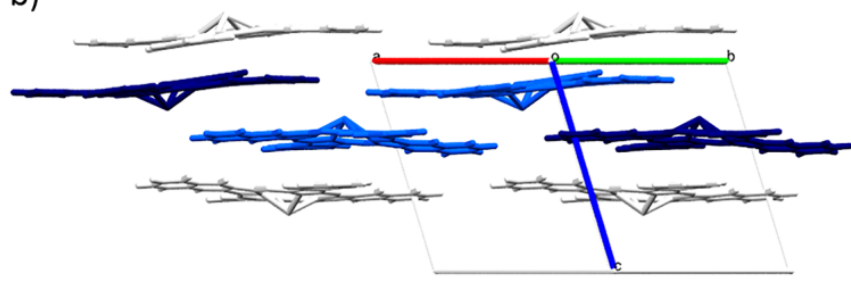

c)

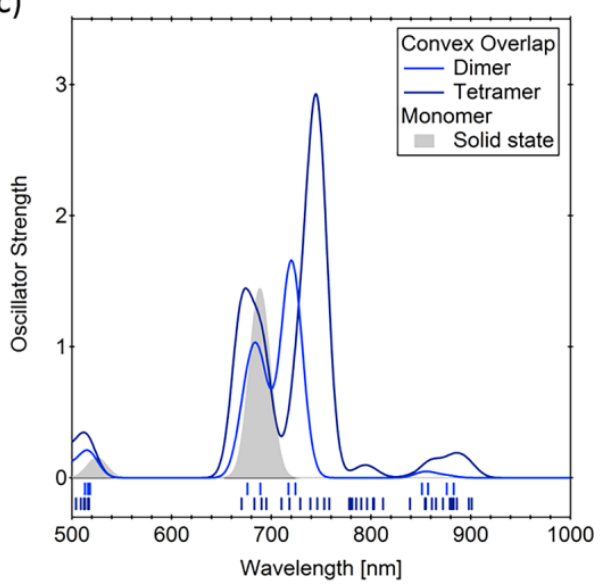

Figure S21: (a \& b) Molecules used to simulate the solid state absorption spectra of SnNPc clusters: (a) concave overlap of dimer (red) and tetramer (red \& brown); (b) convex overlap of dimer (blue) and tetramer (blue \& navy). In both cases, molecules within a layer are related by parallel translation in the plane of the page. (c) Calculated spectra of convex dimer and tetramer clusters, compared to the solid state optimized monomer, showing increased splitting of the Q-band with increasing nearest neighbor interactions. The ticks indicate the energy of the transitions in the dimer and tetramer models. Color schemes in a \& b are consistent with calculated spectra in Figure 4c and Figure S21c. 


\begin{tabular}{|c|c|c|c|}
\hline & Wavelength / nm & Wavenumber $/ \mathrm{cm}^{-1}$ & Oscillator Strength \\
\hline \multirow{2}{*}{ Solution } & 825 & 12,121 & 0.79 \\
\hline & 825 & 12,121 & 0.79 \\
\hline \multirow{4}{*}{ Dimer (convex) } & 724 & 13,812 & 0.79 \\
\hline & 717 & 13,947 & 0.98 \\
\hline & 689 & 14,514 & 0.71 \\
\hline & 676 & 14,793 & 0.54 \\
\hline \multirow{4}{*}{ Dimer (concave) } & 725 & 13,793 & 0.00 \\
\hline & 707 & 14,144 & 1.65 \\
\hline & 681 & 14,684 & 1.23 \\
\hline & 679 & 14,728 & 0.00 \\
\hline \multirow{4}{*}{ Tetramer (convex) } & 746 & 13,405 & 2.60 \\
\hline & 729 & 13,717 & 0.83 \\
\hline & 690 & 14,493 & 0.90 \\
\hline & 670 & 14,925 & 1.24 \\
\hline \multirow{4}{*}{ Tetramer (concave) } & 721 & 13,870 & 2.69 \\
\hline & 715 & 13,986 & 0.48 \\
\hline & 700 & 14,286 & 0.51 \\
\hline & 660 & 15,152 & 1.41 \\
\hline
\end{tabular}




\section{Spectral deconvolution:}

Deconvolution of the experimental UV-Vis spectra of SnNPc and VONPc in solution and as thin films was performed using a home-written addition to the IGOR Pro Multipeak Fitting package. A combination of Gaussian and LogNormal functions were used to achieve a reasonable fit, as well as a power function as baseline to account for background scattering. The goodness of the fit was evaluated by starting from different starting parameters. A minimal but sufficient amount of fitting functions were used, in order to maximize the reproducibility of the fitting profile. Representative fitting profiles for the low energy peak in the solution and thin film (crystalline) spectra of SnNPc are shown in Figure S22. The extracted data from all the fitted spectra are reported in Table S5a and S5b for SnNPc and VONPc, respectively.

a)

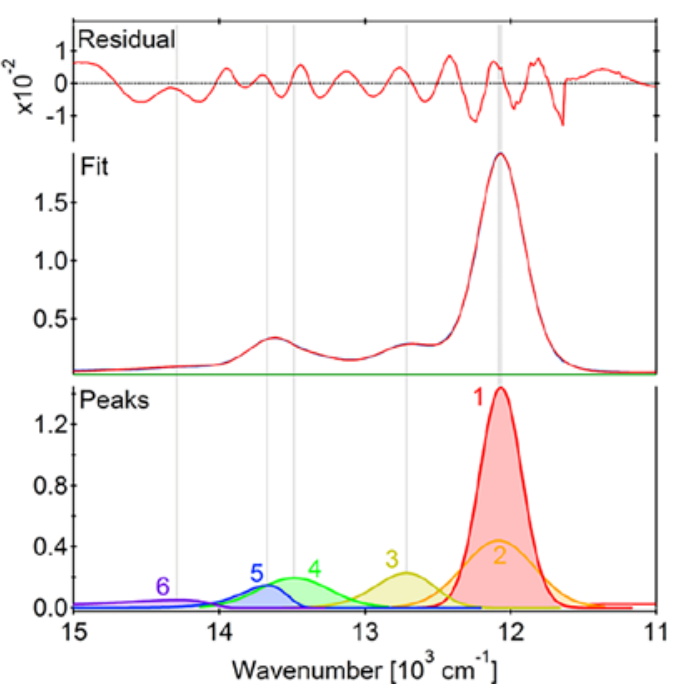

b)

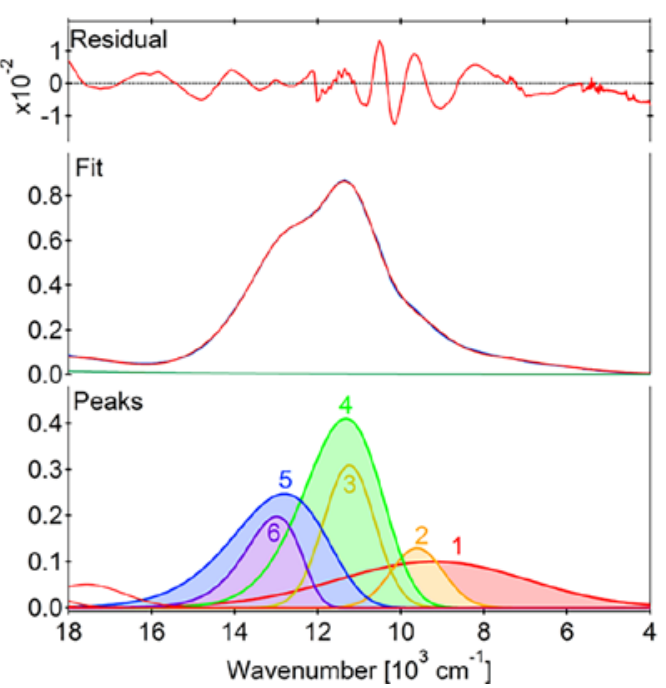

Figure S22: Representative deconvoluted spectra for SnNPc: (a) measured as a solution in 1-chloronaphthalene; (b) measured as a thin film on a quartz substrate (description: crystalline; growth conditions: rate $=0.1 \AA \mathrm{s}^{-1}$, substrate temperature $200^{\circ} \mathrm{C}$ ).

The data reported in Table $\mathrm{S} 5$ is intended as a guide to support the comparison of the experimental spectra with the calculated spectra, and to serve as a reference for future experimental or theoretical works on SnNPc and VONPc. The interpretation of the deconvoluted peaks is not discussed in this manuscript, as a robust assignment of the peaks would require a systematic study of the effect of i.a. film thickness and roughness on the spectral features, combining transmission and reflectance spectroscopy. Furthermore, due to the observed strong effect of crystallinity, crystalline phase and crystalline orientation on the measured spectra, the use of angle-dependent single crystal spectroscopy would greatly benefit the spectral characterization. To date, sufficiently sized single crystals for such measurements have not been achieved.

It should be noted that for the solution spectra of SnNPc and VONPc, the Q-band cannot be fitted adequately with a single peak, but requires a second broader peak of similar wavenumber to describe the peak base (see Peak 2, Fig. S22a). Assuming $C_{4 v}$ in solution, the origin of this second peak is not clear. For the thin film spectra of SnNPc and VONPc, in all cases, an extremely broad peak is required 
to fit the red edge of the NIR peak (see Peak 1, Fig. S22b). While the dimer and tetramer calculations predicted several weak peaks on the low energy tail of the Q-band, it was also observed that its peak height and position are strongly affected by film thickness, whereas the others peaks remain relatively constant, and thus this broad feature could have its origins in interference effects.

\begin{tabular}{|c|c|c|c|c|c|}
\hline & Observed & \multicolumn{4}{|c|}{ Deconvoluted Peaks } \\
\hline & $\begin{array}{c}\lambda_{\mathrm{MAX}} / \\
\mathrm{nm}\end{array}$ & $\begin{array}{c}\text { Wavelength / } \\
\text { nm }\end{array}$ & $\begin{array}{c}\begin{array}{c}\text { Wavenumber / } \\
\mathrm{cm}^{-1}\end{array} \\
\end{array}$ & $\begin{array}{c}\text { Normalized } \\
\text { Height }\end{array}$ & $\begin{array}{l}\text { Width / } \mathrm{cm}^{-1} \\
\text { (skewness) }\end{array}$ \\
\hline \multirow{6}{*}{$\begin{array}{l}\text { Solution } \\
\text { (1-Chloronaphthalene) }\end{array}$} & \multirow{6}{*}{829} & 829 & 12,068 & 1.0000 & 342.1 (1.0045) \\
\hline & & 828 & 12,083 & 0.3049 & $579.5(1.002)$ \\
\hline & & 786 & 12,716 & 0.1574 & 483.2 (1.1362) \\
\hline & & 742 & 13,486 & 0.1354 & $578.3(1.0041)$ \\
\hline & & 731 & 13,672 & 0.1016 & 374.9 (1.5) \\
\hline & & 700 & 14,292 & 0.0355 & 844.9 (2.4593) \\
\hline \multirow{5}{*}{$\begin{array}{l}\text { Amorphous } \\
\left(0.5 \AA \mathrm{s}^{-1} / \mathrm{RT}\right)\end{array}$} & \multirow{5}{*}{860} & 1248 & 8,016 & 0.1111 & $4051.6(1.0415)$ \\
\hline & & 1070 & 9,344 & 0.0196 & $1182.4(2.9775)$ \\
\hline & & 873 & 11,452 & 0.5965 & $3221.6(1.001)$ \\
\hline & & 860 & 11,624 & 1.0000 & $1037.1(1.01)$ \\
\hline & & 770 & 12,988 & 0.6045 & $1841.1(1.6502)$ \\
\hline \multirow{6}{*}{$\begin{array}{l}\text { Crystalline } \\
\left(0.1 \mathrm{As}^{-1} / 200^{\circ} \mathrm{C}\right)\end{array}$} & \multirow{6}{*}{880} & 1087 & 9,200 & 0.2439 & 5382.5 (1.0415) \\
\hline & & 1041 & 9,609 & 0.3150 & $1484.3(1.0004)$ \\
\hline & & 890 & 11,241 & 0.7527 & 1451.9 (1.0117) \\
\hline & & 883 & 11,323 & 1.0000 & 2220.2 (1.2077) \\
\hline & & 781 & 12,802 & 0.6021 & 2707.6 (1.2899) \\
\hline & & 770 & 12,989 & 0.4820 & 1598.8 (1.3647) \\
\hline \multirow{5}{*}{$\begin{array}{l}\text { PTCDA Templated } \\
\left(0.1 \mathrm{As}^{-1} / 150^{\circ} \mathrm{C}\right)\end{array}$} & \multirow{5}{*}{908} & 1110 & 9,007 & 0.1244 & 5117.5 (1.0415) \\
\hline & & 937 & 10,667 & 0.7386 & $554.3(1.0506)$ \\
\hline & & 897 & 11,147 & 1.0000 & 962.5 (1.9678) \\
\hline & & 798 & 12,536 & 0.6079 & $2644.2(1.0013)$ \\
\hline & & 772 & 12,957 & 0.0652 & $1183.6(1.6004)$ \\
\hline \multirow{6}{*}{ SVA (MeOH) } & \multirow{6}{*}{912} & 1053 & 9,495 & 0.0915 & $4530.6(1.0415)$ \\
\hline & & 1026 & 9,749 & 0.0174 & 375.6 (1.01) \\
\hline & & 918 & 10,899 & 0.5159 & 671.8 (1.2752) \\
\hline & & 880 & 11,368 & 1.0000 & 2278.9 (1.01) \\
\hline & & 743 & 13,451 & 0.5364 & 2216.7 (1.2876) \\
\hline & & 682 & 14,653 & 0.0793 & $1265.2(1.2317)$ \\
\hline $\begin{array}{l}\text { SVA (Chlorobenene: } \\
\text { Water) }\end{array}$ & 970 & - & - & - & - \\
\hline \multirow{5}{*}{ SVA (THF) } & \multirow{5}{*}{858} & 941 & 10,629 & 0.7822 & $547.7(1.2)$ \\
\hline & & 927 & 10,789 & 0.6075 & 1573.6 (1.0415) \\
\hline & & 896 & 11,165 & 0.2048 & $5472.1(1.01)$ \\
\hline & & 857 & 11,668 & 0.7950 & $1433.3(1.001)$ \\
\hline & & 766 & 13,052 & 1.0000 & 2282.8 (1.1382) \\
\hline
\end{tabular}




\begin{tabular}{l|c|cccc}
\hline & & 1454 & 6,878 & 0.0745 & $3294.8(1.04)$ \\
SVA (Chloroform) & \multirow{3}{*}{902} & 1167 & 8,566 & 0.1805 & $1545.0(1.0415)$ \\
& & 942 & 10,616 & 0.2171 & $1051.5(1.01)$ \\
& & 861 & 11,613 & 1.0000 & $2979.6(1.001)$ \\
& & 740 & 13,508 & 0.3687 & $2006.2(1.3659)$ \\
\hline \multirow{3}{*}{ SVA (Xylene) } & 1321 & 7,572 & 0.0660 & $3416.9(1.0415)$ \\
& \multirow{3}{*}{828} & 975 & 10,253 & 0.2903 & $1117.8(1.01)$ \\
& & 844 & 11,850 & 0.6061 & $4274.3(1.0119)$ \\
& & 844 & 11,854 & 1.0000 & $1509.5(1.01)$ \\
& & 764 & 13,091 & 0.5169 & $1576.9(1.2379)$ \\
\hline \multirow{3}{*}{ SVA (Acetone) } & 1277 & 7,830 & 0.0682 & $3552.7(1.0415)$ \\
& & 995 & 10,052 & 0.3882 & $1020.9(1.04)$ \\
& \multirow{3}{*}{828} & 840 & 11,899 & 0.4761 & $2204.0(1.01)$ \\
& & 820 & 12,191 & 1.0000 & $3970.6(1.001)$ \\
& & 738 & 13,549 & 0.2419 & $1370.4(1.179)$ \\
\hline
\end{tabular}

Table S5b: Measured spectral peaks for VONPc

\begin{tabular}{|c|c|c|c|c|c|}
\hline & \multirow{2}{*}{$\begin{array}{c}\text { Observed } \\
\lambda_{\mathrm{MAX}} / \\
\mathrm{nm} \\
\end{array}$} & \multicolumn{4}{|c|}{ Deconvoluted Peaks } \\
\hline & & $\begin{array}{c}\text { Wavelength / } \\
\text { nm }\end{array}$ & $\begin{array}{c}\text { Wavenumber / } \\
\mathrm{cm}^{-1}\end{array}$ & $\begin{array}{c}\text { Normalized } \\
\text { Height }\end{array}$ & $\begin{array}{l}\text { Width / } \mathrm{cm}^{-1} \\
\text { (skewness) }\end{array}$ \\
\hline \multirow{6}{*}{$\begin{array}{l}\text { Solution } \\
\text { (1-chloronaphthalene) }\end{array}$} & \multirow{6}{*}{818} & 866 & 11,547 & 0.0359 & 928.19 (1.1347) \\
\hline & & 820 & 12,202 & 1.0000 & 413.29 (1.0001) \\
\hline & & 818 & 12,223 & 0.4489 & 319.56 (1.2081) \\
\hline & & 781 & 12,810 & 0.3124 & 646.77 (1.6419) \\
\hline & & 732 & 13,667 & 0.1576 & $542.05(1.0031)$ \\
\hline & & 713 & 14,028 & 0.0922 & 1210.2 (2.9243) \\
\hline \multirow{5}{*}{$\begin{array}{l}\text { "Amorphous" } \\
\left(<0.4 \AA \mathrm{As}^{-1} / \mathrm{RT}\right)\end{array}$} & \multirow{5}{*}{846} & 1563 & 6,397 & 0.0324 & 2652.7 (1.0415) \\
\hline & & 1104 & 9,056 & 0.1306 & 3023.3 (1.0004) \\
\hline & & 850 & 11,766 & 0.2080 & 805.45 (1.0339) \\
\hline & & 835 & 11,975 & 1.0000 & 3274.9 (1.2262) \\
\hline & & 749 & 13,355 & 0.1553 & $1254.1(1.139)$ \\
\hline \multirow{5}{*}{$\begin{array}{l}\text { Crystalline } \\
\left(<0.2 \text { Ås-1 / } 200^{\circ} \mathrm{C}\right)\end{array}$} & \multirow{5}{*}{864} & 1170 & 8,547 & 0.1702 & $4335.2(1.0415)$ \\
\hline & & 948 & 10,551 & 0.3735 & 2288.3 (1.0004) \\
\hline & & 878 & 11,396 & 1.0000 & 2041.7 (1.5239) \\
\hline & & 859 & 11,638 & 0.5966 & 813 (1.0339) \\
\hline & & 763 & 13,105 & 0.8296 & 2004.9 (1.0037) \\
\hline \multirow{5}{*}{ SVA (Acetone) } & \multirow{5}{*}{860} & 1164 & 8,588 & 0.0969 & 3974.5 (1.0415) \\
\hline & & 1080 & 9,259 & 0.0519 & 1263.9 (1.0004) \\
\hline & & 863 & 11,586 & 0.5240 & 863.41 (1.0339) \\
\hline & & 830 & 12,054 & 1.0000 & 3176.7 (1.2262) \\
\hline & & 752 & 13,297 & 0.2329 & $1114.6(1.139)$ \\
\hline
\end{tabular}



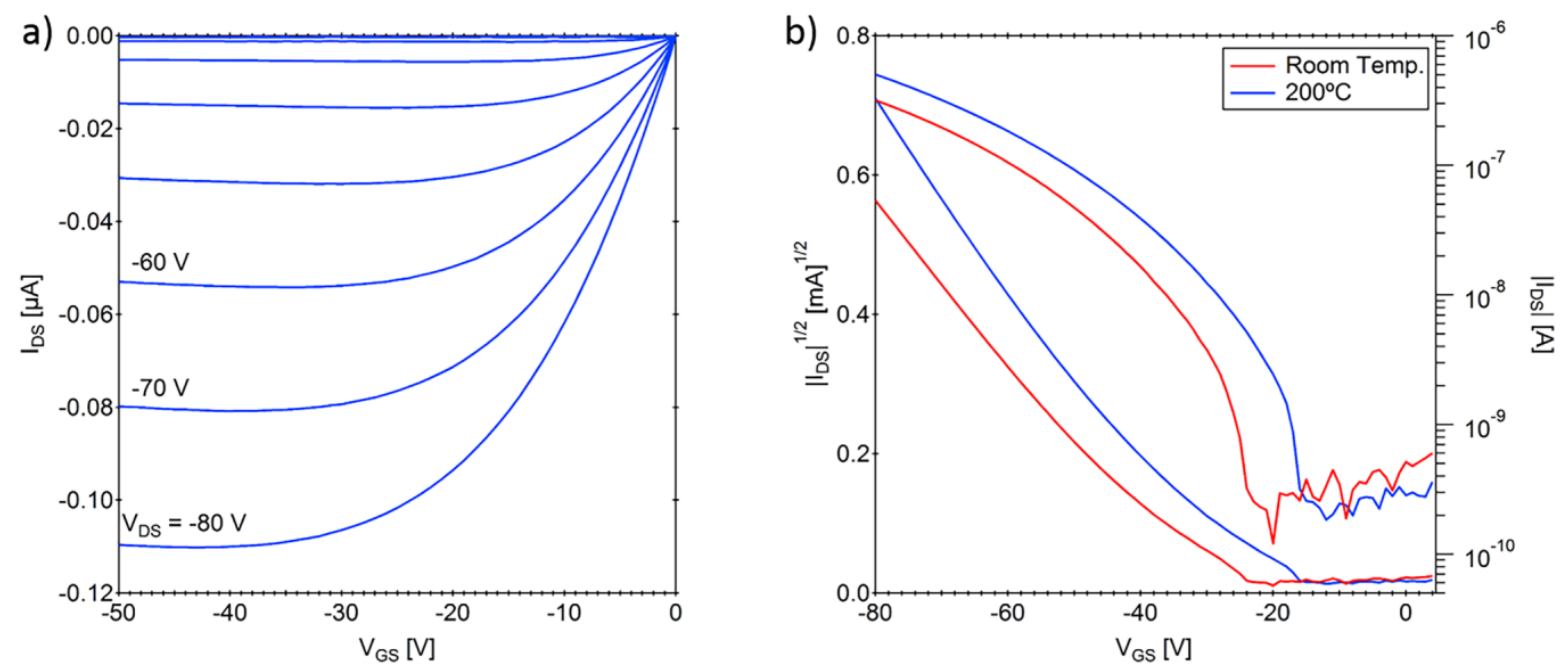

Fig S23: Transistor characteristics for SnNPc deposited at $200^{\circ} \mathrm{C}$, showing (a) output characteristics, and (b) transfer characteristics, compared to a device deposited at room temperature.

In Au bottom contact devices, SnNPc operates as a $p$-type semiconductor with a modest field effect mobility $\mu_{\text {max }}^{+}=4.8 \times 10^{-5} \mathrm{~cm}^{2} \mathrm{~V}^{-1} \mathrm{~s}^{-1}\left(\mu_{\mathrm{av}}^{+}=4.5 \pm 0.3 \times 10^{-5} \mathrm{~cm}^{2} \mathrm{~V}^{-1} \mathrm{~s}^{-1}\right)$ when deposited at room temperature. This is slightly lower than the value reported for VONPc in an identical device configuration $\left(\mu_{\text {max }}^{+} \approx 1 \times 10^{-4} \mathrm{~cm}^{2} \mathrm{~V}^{-1} \mathrm{~s}^{-1}\right)$. [7] Despite a higher crystallinity, SnNPc films deposited at $200^{\circ} \mathrm{C}$ showed only a small improvement in the maximum mobility to $5.6 \times 10^{-5}$ $\mathrm{cm}^{2} \mathrm{~V}^{-1} \mathrm{~s}^{-1}$, but a significant variation between devices $\left(\mu_{\mathrm{av}}^{+}=3 \pm 2 \times 10^{-5} \mathrm{~cm}^{2} \mathrm{~V}^{-1} \mathrm{~s}^{-1}\right)$. It seems therefore that the improvement in crystallinity is balanced by an associated increase in crystalline grain boundaries that can act as carrier traps in the device.
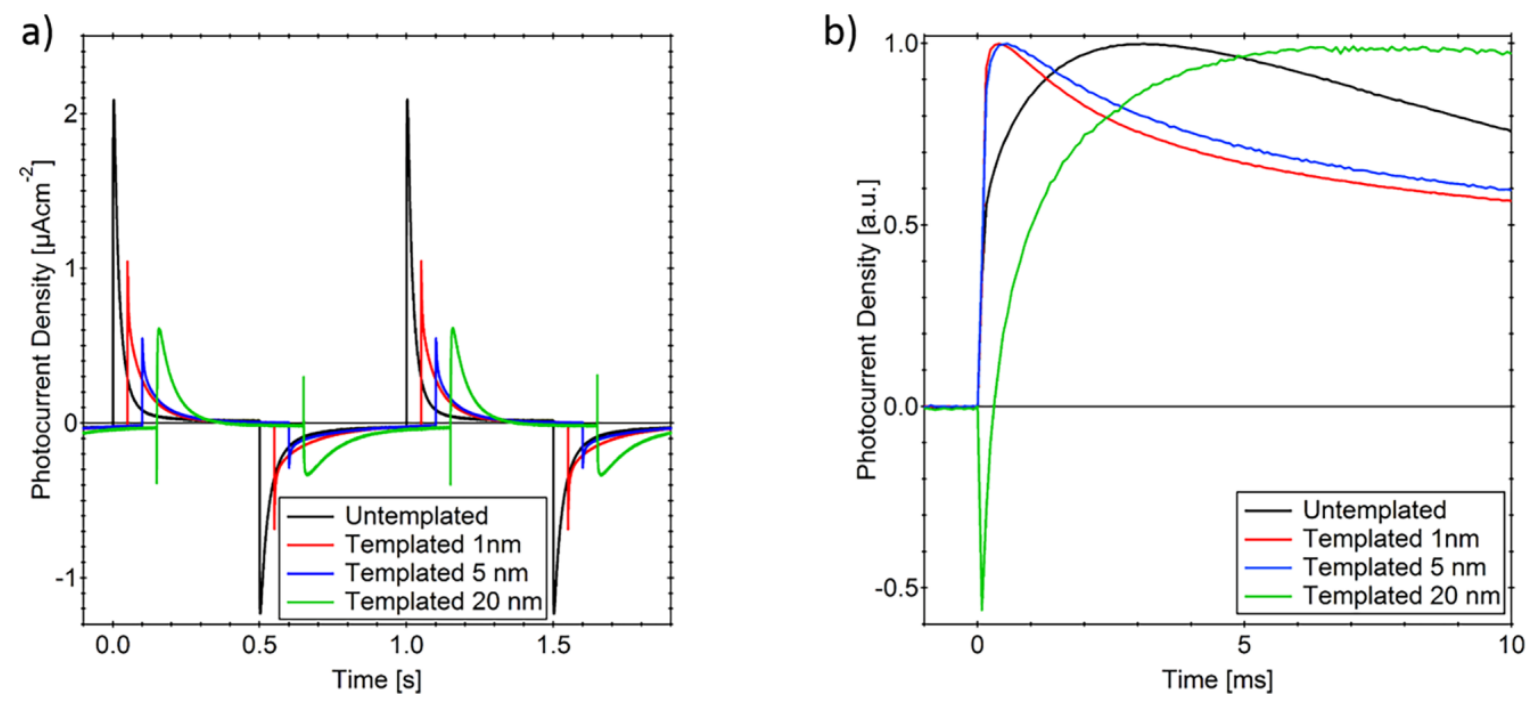

Fig S24: (a) Transient photocurrent response to a square-wave light signal $(\lambda=850 \mathrm{~nm}, f=1 \mathrm{~Hz}$, data offset in $\mathrm{x}$ axis for clarity) for ITO/PTCDA $(d=x \mathrm{~nm}) / \mathrm{SnNPc}\left(d=75 \mathrm{~nm}, 150^{\circ} \mathrm{C}\right) / \mathrm{IL} / \mathrm{Ag}$ devices, where $x=0,1,5$ and $20 \mathrm{~nm}$, and IL is the ionic liquid MEMP-TFSI; (b) expansion of normalized photocurrent rise. 

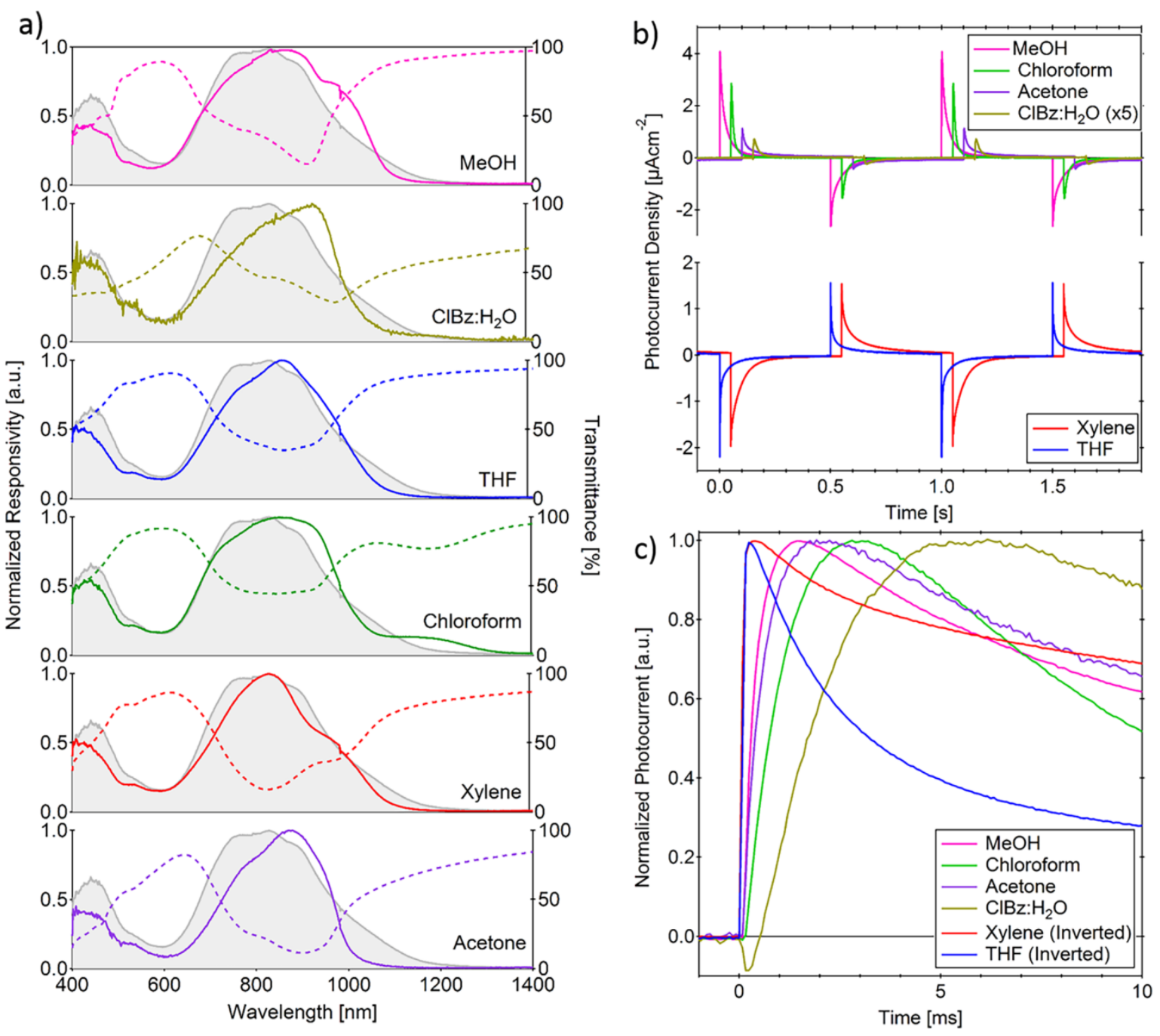

Fig S25: Photodetector characterization for ITO/SnNPc(75nm)/IL(MEMP-TFSI)/Ag devices following solvent vapor annealing: (a) photocurrent action spectra of solvent annealed films (solid lines; unannealed active layer shown as shaded gray for comparison), compared to the transmission spectra of the SVA thin films deposited on ITO substrates (broken lines); (b) transient photocurrent response to a square-wave light signal ( $\lambda=850 \mathrm{~nm}, f=1 \mathrm{~Hz}$, data offset in $\mathrm{x}$-axis for clarity) for solvent annealed films, showing an inverted photocurrent polarity for xylene and THF compared to unannealed and other SVA films; (c) expansion of normalized photocurrent rise for solvent annealed films. 


\section{REFERENCES}

[1] PDXL Version 1.8.1, Rigaku Corporation: Tokyo, Japan.

[2] Reissig, L.; Mori, K.; Treadwell, R.; Dalgleish, S.; Awaga, K. Factors Affecting the Polarity and Magnitude of Photoresponse of Transient Photodetectors. Phys. Chem. Chem. Phys. 2016, 18, 6821-6830.

[3] Hiller, W. Strähle, J.; Kobel, W.; Hanack, M. Polymorphie, Leitfähigkeit und Kristallstrukturen von Oxo-phthalocyaninato-titan(IV). Z. Kristallog. 1982, 159, 173183.

[4] Oka, K.; Okada, O.; Nukada, K. Study of the Crystal Structure of Titanylphthalocyanine by Rietveld Analysis and Intermolecular Energy Minimization Method. Jpn. J. Appl. Phys. 1992, 31, 2181-2184.

[5] Saito, T.; Sisk, W.; Kobayashi, T. Suzuki, S.; Iwayanagi, T. Photocarrier Generation Processes of Phthalocyanines Studied by Photocurrent and Electroabsorption Measurements. J. Phys. Chem. 1993, 97, 8026-8031.

[6] Saito, T.; Iwakabe, Y.; Kobayashi, T.; Suzuki, S.; Iwayanagi, T. Thermochromism of Specific Crystal Form Oxotitanium Phthalocyanines Studied by Electroabsorption and X-ray Diffraction Measurements. J. Phys. Chem. 1994, 98, 2726-2728.

[7] Dalgleish, S.; Reissig, L.; Hu, L.; Matsushita, M. M.; Sudo, Y.; Awaga, K. Factors Affecting the Stability and Performance of Ionic Liquid-Based Planar Transient Photodetectors. Langmuir 2015, 31, 5235-5243. 